\title{
MicroRNAs Role in Non-Communicable Diseases and Link to Multidrug Resistance, Regulation or Alteration
}

\author{
Marwa M. Mahmoud, Eman F. Sanad and Nadia M. Hamdy* \\ Biochemistry Department, Faculty of Pharmacy, Ain Shams University, 11566, Abassia, Cairo, Egypt; \\ Marwa.M.Mohamed@pharma.asu.edu.eg; dr.emansanad@pharma.asu.edu.eg \\ * nadia hamdy@pharma.asu.edu.eg, orcid.org/0000-0003-2105-107X
}

\begin{abstract}
Discovery of microRNAs (miRNAs) twenty years ago, has advocated a new era of "Molecular Genetics". About 2000 miRNAs are present, that regulate one third of the genome. MiRNAs dysregulated expression may contribute to several diseases including tumor growth. Their presence in body fluids, reflecting levels alteration in various cancers, merit circulating miRNAs as the "next generation biomarkers" for early stages tumor diagnosis and/or prognosis. Herein, we performed a comprehensive literature search focusing on the origin, biosynthesis and role of miRNAs and summarized the foremost studies centering on miRs value as non-invasive biomarkers in different non-communicable diseases, including various cancer types. Moreover, during chemotherapy many miRNAs were linked to multidrug resistance, via modulating numerous biological processes and/or pathways that will be highlighted as well.
\end{abstract}

Keywords: ncRNA; miR; NCDs; onco-miR; cancer; mTOR

\section{MicroRNAs History/Background}

\subsection{MicroRNA; the Protein Short Non-coding RNAs}

The human genome reveals that the protein-coding genes can be as few as 25,000[1]. Despite the fact that the exact number of coding genes, within the human genome, is unknown, protein non-coding genes make up a significant portion of the human genome[2].

Human cells contain several distinguishing sequences of non-coding RNA (ncRNA) that could be categorized into two major classes: long ncRNA ( $\geq 200$ nucleotides length) and short ncRNA $(<200$ nucleotides). The short ncRNA group comprises different classes such as small-interfering RNAs (siRNA), small nuclear RNAs (snRNAs), small nucleolar RNAs (snoRNAs), piwi-interacting RNAs (piRNAs) and microRNAs (miRNAs)[3] .

\subsection{MiRNAs are the Essential Gene-Expression Regulatory Molecules}

MiRNAs regulate one-third of the human genome[4]. These are small single-stranded 17-25 nucleotides, recently known as essential gene-expression regulatory molecules[5].

The parent microRNAs member is lin-4, that has been discovered within a nematode called Caenorhabditis Elegans. Lin-4 was found to play a pivotal role in the transition from a larval stage into another, via suppression of lin-4 gene, concerned with larval development[6].

MiRs are encoded either via separate transcription units within the pre-mRNA introns or via multi-cistronic clusters[7]. MiRNAs organized in clusters within the genome, are sharing the same transcriptional regulatory elements, but are expressed individually, in the event, as if they have their own promoters[8].

MiRs direct major cellular functions such as proliferation, differentiation, maturation, and metabolism[9]. Irregular expression of miRNAs may occur in a range of distinctive pathologies, with striking modifications in tumor tissues[9]. Profiling of miRNAs has contributed to the molecular classification of tumors. The presence of miRNAs in body fluids as urine, serum or plasma, CSF, and tears, permitted 
non-invasive identification of various cancer types[10], [11], [12], [13] considered as beneficial potential liquid biopsy.

\section{Review Aims}

2.1. In Part I, the review aims to briefly discuss "miRs biosynthetic pathways and down-stream effects upon binding target $m R N A$ ”.

2.2. In Part II, the review aims to highlight "the utility of circulating miRNAs as biomarkers for non-communicable diseases (NCDs) and a brief about their role in cancer growth or resistance to treatment”.

\section{Review Methodology}

An online search in the medical databases PUBMED and NCBI for the following terms: ("Circulating miRNA") AND ("Health and diseases regulation of gene expression") AND ("Role in Carcinogenesis") AND ("Epigenetics") AND ("Future promising biomarkers") was done on September, 2020, with publication date limit since 2015. Priority was given to papers with higher empirical evidence methodology, including clinical guidelines, meta-analysis, randomized clinical studies, systematic review, original papers, and narrative reviews.

\section{Part I.}

\section{MiRNAs Biogeny}

MiRNAs biogenesis include various coordinated steps and specific cellular mechanisms[8]. Biogenesis of miRNA starts with post-transcriptional or co-transcriptional preparation of RNA polymerase II-III transcripts. Around $50 \%$ of the miRNAs recently identified are intragenic and are typically regulated from introns and some protein-coding gene exons. The remaining ones are intergenic, freely transcribed and guided according to their own promoters from a host gene[14]. MiRNAs could be translated as a single long transcript, named clusters[15]. Moreover, miRNAs biogenesis is categorized as either canonical or non-canonical.

\subsection{Canonical miRNAs Biogeny Pathway}

This is the main route by which miRNAs are developed, as shown in Figure (1). In this process, primary-miRNAs (pri-miRNAs) are transcribed from their genes by RNA polymerase II. Which is then handled by a microprocessor complex composed of DiGeorge Syndrome Critical Region 8 (DGCR8); an RNA-binding protein, Drosha, a Class 2 ribonuclease III enzyme into precursor-miRNAs (pre-miRNAs)[16]. In this process, DGCR8 identifies an N6-methyl adenylated GGAC and a different motif within the pri-miRNA[16], while Drosha begins processing inside the nucleus by cutting the stem-loop precursor[17].

For most of the double stranded RNAs (dsRNAs) which are involved in small-RNA production routes, pre-miRNA seems to be a signature motif. This signature is recognized by the Exportin-5 protein; that facilitates the release of pre-miRNAs to the cytoplasm, through nuclear pores, depending on a GTP-GDP gradient[17]. Exported pre-miRNA is transferred to another RNase-III enzyme in the cytoplasm, called Dicer. Dicer, the cytoplasmic RNase-III enzyme, cuts the pre-miRNA to a miRNA duplex, which is un-winded afterwards giving the "Fully Developed Functional miRNA" molecule.

In an ATP-dependent manner, the two strands defined from the resultant miRNA duplex, might be stacked into the protein family Argonaute (AGO) known as AGO1-4[18]. After miRNA duplex formation, one strand of the miRNA associates with an RNA-induced silencing complex (RISC) forming the "regulatory miRNA-RISC complex". The choice of strands $5 p$ or $3 p$ is dependent on the thermodynamic stability at the 5 ' untranslated regions (UTRs) at the 1-position of the nucleotide[19]. The unoccupied strand known as the 
passenger strand is loosened by different components from the loaded strand, named the guide or leading strand, depending on complementarity[6].

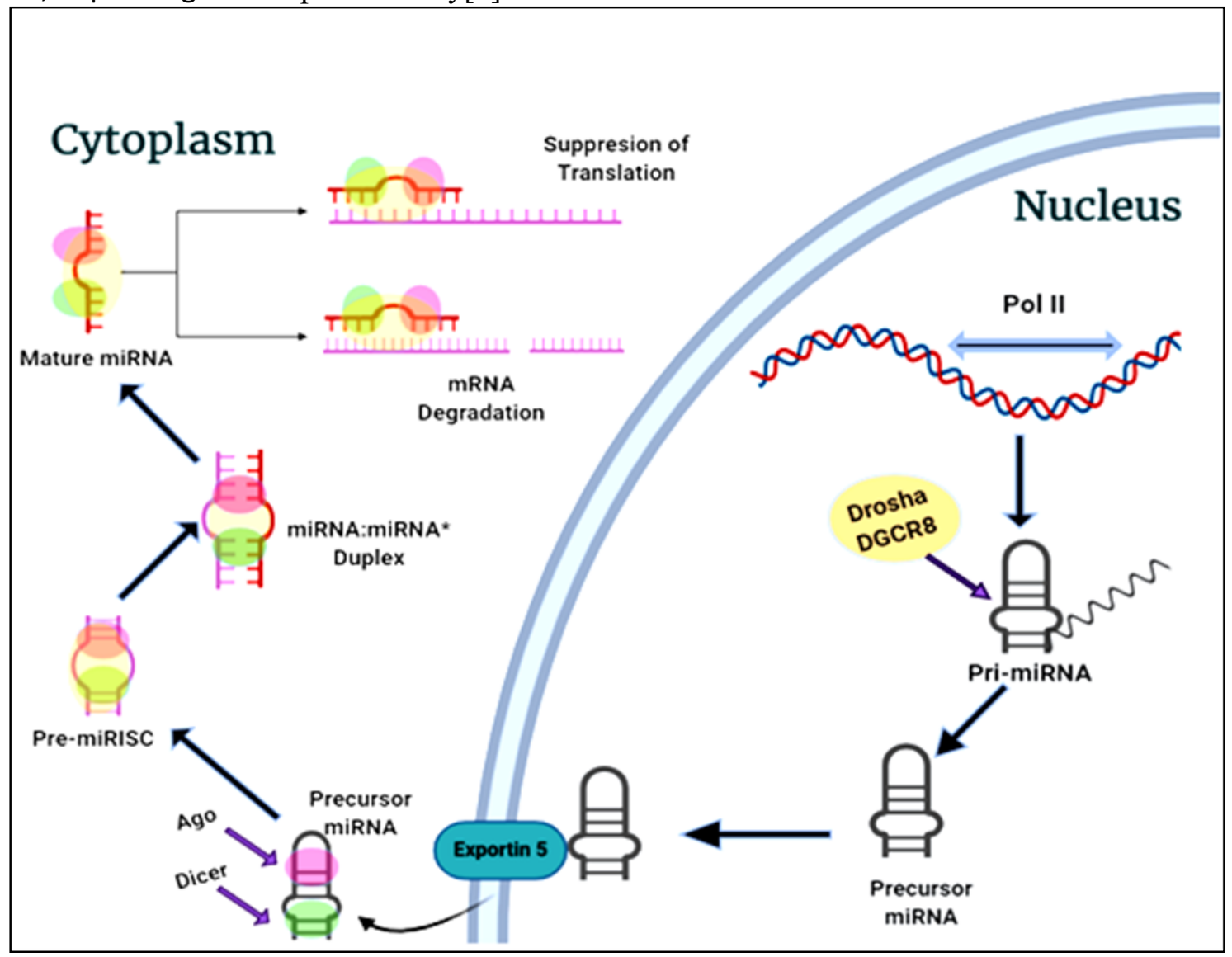

Figure 1: Canonical miRNAs Biogeny Pathway

[It is the primary route by which miRNAs are produced. In the nucleus, the gene is transcribed to generate primary miRNA (pri-miRNA) that is cleaved producing precursor miRNA (pre-miRNA), which is then exported to the cytoplasm to be broken, resulting in miRNA duplex. miRNA duplex links to RISC complex resulting in miRNA duplex unwinding to create a mature miRNA. Every mature miRNA binds to its target mRNA, resulting in silencing by cleavage, de-adenylation or repressing translation.]

\subsection{Non-Canonical miRNAs Biogenic Pathway}

Several non-canonical pathways have been illustrated to date, primarily Drosha/DGCR8-independent and dicer-independent pathways[6].

\subsubsection{Drosha/DGCR8-Independent Non-Canonical MiRNAs Pathway}

This pathway joins mRNA introns and their own transients to "mirtrons transcripts". Drosha/DGCR8 is skipped at that stage of processing and these transcripts are, again, carried by the protein Exportin-1 to the cytoplasm[17].

\subsubsection{Dicer-Independent miRNAs Biogenic Pathway}

mRNAs could be dealt by Drosha/DGCR8 to form short heterogeneous RNA (shRNA). Since these transcripts are not lengthy to serve as dicer substrates, AGO2 protein leads in their cytoplasmic developmental steps[20], as previously mentioned. 


\section{MiRNAs-Target Binding}

Via complementarity between unique sequences, which are 2-7 bases, from the 5' end of the miRNA and certain target mRNA sequences, recognized as "miRNA Response Elements" (MREs), the developed miRNA attaches to its target[21].

\subsection{MiRNA-Target Gene mRNA-Binding Types}

5.2.1. Ideal Binding where complete complementarity occurs when miRNA binds its target ORF resulting in an "RNA Decay" or

5.2.2. Imperfect Binding resulting in "Post-Transcriptional Silencing" via mRNA de-stabilization, de-capping, de-adenylation and translational repression[6]'[22].

It is worthy to mention the fundamental multifaced aspect of miRNAs target binding, is that their suppressive role is not limited to one-mRNA, highlighting the "One-mRNA Paradigm" in which multiple mRNA targets can be achieved by one microRNA and multiple microRNAs can hit one mRNA[23].

5.3. MiRNA-Target Gene(s) mRNA Silencing Mode(s)

Depending on the degree of MREs complementarity, the target gene(s) mRNA silencing strategies, by miRNAs, could be attained either via target gene mRNA degradation or target gene mRNA translation repression.

\subsubsection{Target mRNA Decay}

MiRNA-induced silencing complex (miRISC) AGO proteins bind to the GW182 (a protein-containing glycine-tryptophan repeat) to enroll the "de-adenylase complex" and promote de-adenylation of the target gene mRNA poly(A) tail. With the aid of the catalytic de-capping protein-2 (DCP2), after de-adenylation, and in the presence of an additional de-capping activators, miRISC de-caps the de-adenylated gene mRNAs. In the presence of an enhancer of de-capping 4 (EDC4), DCP1 and additional de-capping cofactors, the decay of the target mRNA is aided by the cytoplasmic 5' to $3^{\prime}$ exonuclease1 (Xrn1p)[24]

\subsubsection{Target mRNA Translation Repression}

miRNA-mediated target mRNA translational repression can occur before and after translational initiation step, through several mechanisms.

5.3.2.1. miRISC ties to the target mRNA at that point AGO protein interacts with the GW182. This interaction promotes the relocation of poly(A) binding protein from the 3' poly(A)-tail and blocks its binding to the eukaryotic initiation factor 4 complex (eIF4G), interfering with the "translation-initiation step" [25].

5.3.2.2. Repressing cap-structure recognition by eIF4F complex where the AGO protein separates the eIF4A from the 5' cap binding complex of the target mRNA and therefore, the ribosomal subunit will not be recruited or attached to the mRNA for translation initiation[25].

5.3.2.3. miRNA can repress protein synthesis after target mRNA translation initiation.

5.3.2.4. Additionally, miRISC could interferes with the targeted mRNA elongation components[25].

5.3.2.5. Finally, to ensure no escape from miR silencing effect, if the target mRNA was translated, miRISC could recruit proteases resulting in degradation of the nascent polypeptide chains[25]. 


\subsection{MiRNA-Target Gene(s) Activation Mode}

Activated targeted mRNA expression could be triggered by miRNAs[6], via AGO2 protein and fragile-X-mental retardation related protein-1, rather than GW182. This is achieved via MiR attachment on the target promoter, to induce RNA-Polymerase II recruitment followed by transcription activation[26].

Either "MiR-target gene(s) binding" resulted in an expression silencing or activation, these effects have been witnessed and recorded by researchers to be associated with various disease(s), that will be discussed in the current review Part II.

\section{Part II.}

\section{MiRNAs Expression Alterations in Non-Communicable Diseases}

\subsection{MiRNAs Relation to Glucose Homeostasis}

MiRNAs Effect on Adipogenesis, Metabolic Syndrome or Weight Control[27] MiRNAs may boost or inhibit mesenchymal stem cell adipogenic differentiation (Table 1). MiRs establish adipocyte differentiation, through directing adipogenesis-related transcription components and signal transduction pathways[28]. This could be mediated via AKT/mTOR signaling pathway, with an effect on glucose homeostasis and adipogenesis increment, characterized by the final up-regulation of adipogenic markers[29]. On the other hand, miRNAs would repress adipogenic differentiation via adipogenic factors down-regulation, together with a decreased triacylglycerol level[30].

\subsubsection{MiRNAs Relation to Type 2 Diabetes Mellitus}

As listed in Table 1, many miRNAs are linked to $\beta$-cells growth, insulin resistance or sensitivity, insulin production/secretion and insulin signaling, which can influence T2DM disease course[31]. Therefore, diabetes-related nephropathy or retinopathy is also affected by an altered microRNAs expression[32].

\subsubsection{MiRNAs Lists in Cardiovascular Diseases}

miRNAs regulate the cardiac progenitor cells differentiation and proliferation, controlling cardiac myocytes, endothelial cells, pacemaker cells, as well as smooth muscle cells function. Table 2 shows miRNAs lists dysregulated in various CVDs[33]. For example, miR-208a and miR-208b, encoded within alpha and beta-cardiac muscle myosin heavy chain genes, respectively, were found to be elevated in patients with acute myocardial infarction (AMI). Liu and his co-workers[34] demonstrated a significant predictive value for miR-208, miR-1 and miR-499 in AMI, higher than the traditional cardiac biomarkers, namely, TnT and CPK-MB.

\subsection{MiRNAs List in Cerebrovascular Diseases}

miRNAs are essential to the nervous system's improvement, with few miRNAs having function in developing ischemic cerebrovascular disorders incapacity[35]. Many miRNAs have been associated with post-stroke brain edema and post-stroke cell death, namely, apoptosis.[36]As listed in Table 3.

\subsection{MiRNAs in the Oncology field}

\subsubsection{Onco-miR or Tumor Suppressor miR; a Coin with Two Faces}

Being a multifactorial player, miRNA in the oncology field represents a coin with two faces, either oncogenic or tumor suppressor[37], as listed in Table 4. miRNAs that can hit/suppress various mediators of the oncogenic signaling pathways, is known as a tumor suppressor mediator[38],[39],[40].

On the contrary, the miRNA that aims the cell-cycle checkpoint proteins or the fundamental tumor suppressor proteins, is nominated the oncogenic miRNA or an onco-miR[41]. 
Table 1: MiRNAs List in relation to Glucose Homeostasis; Adipogenesis, Metabolic Syndrome, and Type 2 D.M

\begin{tabular}{|c|c|c|}
\hline Metabolic Disease & miRNAs Effect & miRNAs List \\
\hline Obesity \& & Adipogenesis promoting & miR-26b[42], miR-103[43], miR-146b, miR-148a[44], miR-199a, miR-181, miR-320[28] \\
\hline Metabolic Syndrome & Anti-adipogenic & miR-33b, miR-93[45], miR-125a, mirR-193a/b[46], miR-194, miR-363, miR-709[27] \\
\hline \multirow[t]{4}{*}{ Type 2 D.M } & ß-cells development & $\begin{array}{l}\text { miR-197-3p, miR-9-5p, miR-9- 3p, miR-99a-3p, miR-124a, miR-135a, miR-138, miR-149, } \\
\text { miR-342-3p, miR-375, miR-106b, miR-222[47]'[48]'[49]'[50]'[51]'[52]'[53] }\end{array}$ \\
\hline & Insulin sensitivity/resistance & $\begin{array}{l}\text { miR-31, miR-127, miR-302c3p, miR-373, miR-518b, miR-520c-3p, miR-200, } \\
\text { miR-7[54],[55],[56],[57],[51] }\end{array}$ \\
\hline & Insulin production/secretion & $\begin{array}{l}\text { miR-29, miR-221, miR-222, miR-103, miR-107, miR-223[58] miR-320, miR-126, miR-103, } \\
\text { miR-107[59]'[31] Let-7 family[60] miR-375, miR-9, miR-7, miR-124a, miR-96, miR-124, } \\
\text { miR-184, miR-29a[47]'[51] }\end{array}$ \\
\hline & Insulin signaling & miR-7, miR-1, miR-133a/b miR-206, miR-128a, miR-330, miR-223[61]'[62]'[63] miR-144 \\
\hline
\end{tabular}

Table 2: MiRNAs Lists associated with different Cardiovascular Diseases

Cardiovascular Disease(s) miRNAs List

\begin{tabular}{ll}
\hline Acute Myocardial Infarction & miR-208a/b, miR-1, miR-133a/b, miR-499[34], miR-328, miR-134, miR-1291, miR-663b, miR-22[64], \\
& miR-126[65] \\
Heart Failure & miR-423-5p, miR-22, miR-320a, miR-92b[33], miR-21[66] \\
Atrial Fibrillation & miR-133b, miR-328[20], miR-499[67], miR-126[68] \\
Hypertension & miR-34a, miR-21[69], miR-23b, miR-191, miR-451, miR-126-3p, miR-26a-5p, miR-107[70] \\
\hline
\end{tabular}




\section{Table 3: MiRNAs List in some Cerebrovascular Diseases}

\begin{tabular}{|c|c|c|}
\hline $\begin{array}{l}\text { Cerebrovascular } \\
\text { Disease(s) }\end{array}$ & $\begin{array}{l}\text { miRNA Regulatory } \\
\text { Effect }\end{array}$ & miRNAs List \\
\hline \multirow[t]{2}{*}{ Stroke } & Up regulation & $\begin{array}{l}\text { miR-125b-2, miR-422a, miR-488, miR-627[71], miR-290[72], miR-124, miR-27a, miR-10a, miR-182, } \\
\text { miR-200b[73], miR-298, miR-106b-5P, miR-4306[74] }\end{array}$ \\
\hline & Down regulation & $\begin{array}{l}\text { let-7f, miR-126, miR-1259, miR-142-3p, miR-15b, miR-186, miR-519e, miR-768-5p[35], miR-320e, } \\
\text { miR-320d[35] }\end{array}$ \\
\hline \multirow[t]{2}{*}{ Alzheimer's } & Up regulation & $\begin{array}{l}\text { miR-146a[75], miR-361-5p, miR-30e-5p, miR-93-5p, miR-15a-5p, miR-143-3p, miR-106b-5p, miR-101-3p, } \\
\text { miR-424-5p, miR-106a-5p, miR-18b-5p, miR-3065-5p, miR-20a-5p, miR-582-5p[76] }\end{array}$ \\
\hline & Down regulation & miR-31, miR-93, miR-143, miR-146a[75], miR-1306-5p, miR-342-3p, miR-15b-3p[76] \\
\hline \multirow[t]{2}{*}{ Parkinson's } & Up regulation & miR-331-5p[77], miR-137-3p, miR-124-3p[78], miR-30a/b-5p[79] \\
\hline & Down regulation & miR-29a/c-3p, miR-19a/b-3p[80] \\
\hline
\end{tabular}


Table 4: miRNAs Lists associated with Various Types of Cancer and their effects either oncogenic or tumor suppressor

\begin{tabular}{|c|c|c|}
\hline Cancer Type & miRNA Role & miRNAs List \\
\hline Leukemia & Tumor Suppressor & $\begin{array}{l}\text { miR-128a, } \quad \text { miR-128b, } \\
\text { miR-181b-5p, miR-423-3p, miR-486-5p, miR-92b-3p[81] } \\
\text { miR-15a, miR-16-1[82], miR-495 }\end{array}$ \\
\hline Breast & $\begin{array}{l}\text { Oncogenic } \\
\text { Tumor Suppressor }\end{array}$ & $\begin{array}{l}\operatorname{miR}-1285[83], \text { miR-10b, miR-373[37], miR-520c, mir-21, mir-155 } \\
\text { mir-125a/b, miR-142[84], miR-124-3p[85], miR-101, miR-204-5p[86], miR-491-5p[87], } \\
\text { miR-491-5p[87], miR-206[88], miR-152[89], miR-142-3p[90] }\end{array}$ \\
\hline Gastric & enic & 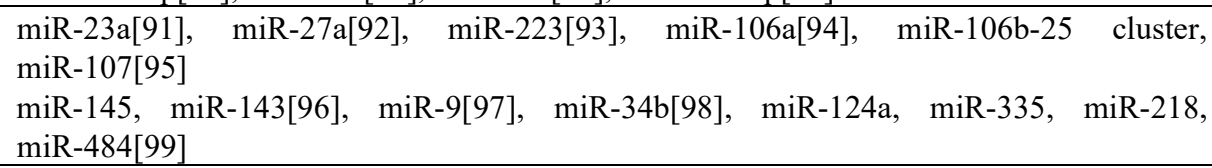 \\
\hline HCC & $\begin{array}{l}\text { Oncogenic } \\
\text { Tumor Suppressor }\end{array}$ & $\begin{array}{l}\text { miR-182-5p[100], miR-106b-3p, miR-101-3p, miR-1246[101], miR-221, miR-224 } \\
\text { miR-34a, miR-199a[102], miR-200a }\end{array}$ \\
\hline Prostate & $\begin{array}{l}\text { Oncogenic } \\
\text { Tumor Suppressor }\end{array}$ & $\begin{array}{l}\text { miR-141 and miR-21[103], miR-125b[104] } \\
\text { miR-145, miR-143[105] }\end{array}$ \\
\hline Pancreatic & Oncogenic & $\begin{array}{l}\text { miR-132, miR-212, miR-122-5p, miR-125b-5p, miR-192-5p, miR-193b-3p, miR-221-3p, } \\
\text { miR-27b-3p[106], miR-222[66], miR-181a/b/d[107], miR-155, miR-103, miR-107 } \\
\text { miR-125b-5p[106], miR-34a, miR-96, miR-221 }\end{array}$ \\
\hline Ovarian & Oncogenic & 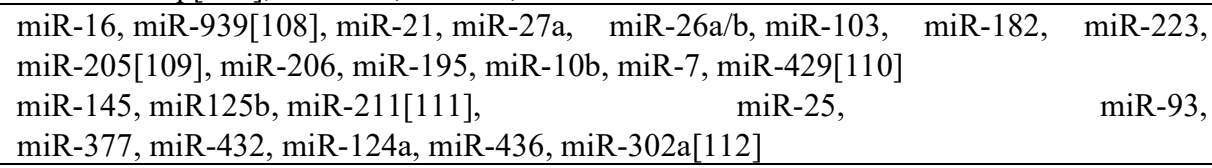 \\
\hline $\begin{array}{l}\text { Uterine } \\
\text { Leiomyoma }\end{array}$ & sor & $\begin{array}{l}\mathrm{miR}-15 \mathrm{~b}[113] \\
\mathrm{miR}-29 \mathrm{a} / \mathrm{b} / \mathrm{c}, \mathrm{m}\end{array}$ \\
\hline Thyroid & $\begin{array}{l}\text { Oncogenic } \\
\text { Tumor Suppressor }\end{array}$ & $\begin{array}{l}\text { mir-129-1, miR-146b, mir-183, mir-197 [114], miR-146b[115] } \\
\text { miR-338-3p[116], miR-497[117] }\end{array}$ \\
\hline Colorectal & Oncogenic & $\begin{array}{l}\text { miR-1246, miR-1308, miR135b-5p, miR-183-5p, miR-18a-5p, } \operatorname{miR} 18 b-5 p, \\
\text { hsa-miR-21-5p, miR-223-3p, miR-224- 5p, miR-503-5p[118] } \\
\text { miR-1-3p, miR-133b, miR-143-3p, miR145-5p, miR-150-5p, miR-195-5p, miR215-5p, } \\
\text { miR-375, miR-378-3p, miR497-5p[118] }\end{array}$ \\
\hline Melanoma & $\begin{array}{l}\text { Oncogenic } \\
\text { Tumor Suppressor }\end{array}$ & $\begin{array}{l}\text { miR-195[119], miR-210[120] } \\
\text { miR-193a, miR-33a[121]miR-let-7b/c }\end{array}$ \\
\hline & Oncogenic & $\begin{array}{l}\text { miR-128a, miR-155, miR-516a-3p, miR-372, miR-181b-5p, miR-181d, miR-191-3p, } \\
\text { miR-598[122] } \\
\text { miR-34a[123], miR-3676-5p, miR-383[122] }\end{array}$ \\
\hline $\begin{array}{l}\text { Osteosarcom } \\
\text { a }\end{array}$ & Oncogenic & miR-504[124], miR-149[125] \\
\hline $\begin{array}{l}\text { Neuroblasto } \\
\text { ma }\end{array}$ & Tumor Suppressor & $\begin{array}{l}\text { miR-181a/b[126], miR-1268, miR-1303[127], miR-1308, miR-1908, } \\
\text { miR-513/b-5p, miR-548h, miR-580 } \\
\text { miR-513, miR-548a/f-5p, miR-323-5p, miR-342[128], miR-639, miR-640, } \\
\text { miR-662, miR-34a[129], miR-16, miR-15a/b[130] }\end{array}$ \\
\hline $\begin{array}{l}\text { Lung non- } \\
\text { small cell }\end{array}$ & $\begin{array}{l}\text { Oncogenic } \\
\text { Tumor Suppressor }\end{array}$ & $\begin{array}{l}\text { miR-25[131], miR-7, miR-34a, miR-328-3p[132], miR-499a[133] } \\
\text { miR-451[134], miR-214 }\end{array}$ \\
\hline Bladder & $\begin{array}{l}\text { Oncogenic } \\
\text { Tumor Suppressor }\end{array}$ & $\begin{array}{l}\text { miR-222, miR-452, miR-6724-5p, miR-1185-1-3p, miR-6831-5p[135] } \\
\text { miR-143, miR-99a-5p[136], miR-6087, miR-3960, miR-1343-5p[135] }\end{array}$ \\
\hline Cervical & $\begin{array}{l}\text { Oncogenic } \\
\text { Tumor } \\
\text { Suppressor }\end{array}$ & $\begin{array}{l}\text { miR-31[137], miR-19a/b, miR-145[138]miR-155[139]miR-125a[140] } \\
\text { miR-34a[141], miR-886-5p[142] }\end{array}$ \\
\hline
\end{tabular}

\subsubsection{MiRNAs Involvement in Carcinogenesis via mTOR Signaling}

In different types of cancer, the mechanistic target of rapamycin (mTOR); a conserved serine/threonine kinase enzyme involved in cell metabolism, could be hyperactive, leading to an abnormal cell proliferation 
and eventually cancer[143]. An association was observed between miRNA(s) and the mTOR pathway during cancer growth[143].

\subsubsection{1. mTOR Signaling Pathway link to miRNA Biogenesis}

Targeted Raptor mutation, a fundamental component of mTORC1 type, may affect increments in miRNA biogenesis[144]. On the other hand, Mdm2-dependent ubiquitination of Drosha, an RNase assigned to pri-miRNA formation to give pre-miRNA, therefore, mTOR activation widely suppresses miRNA biogenesis[144].

Few specific miRNA(s)-related to cancer are known to be regulated by mTOR signaling, as sketched in Figure (2).

However, many miRNAs have been documented to target various mTOR signaling stages in different types of cancer, as shown listed in Table $\mathbf{5}$.

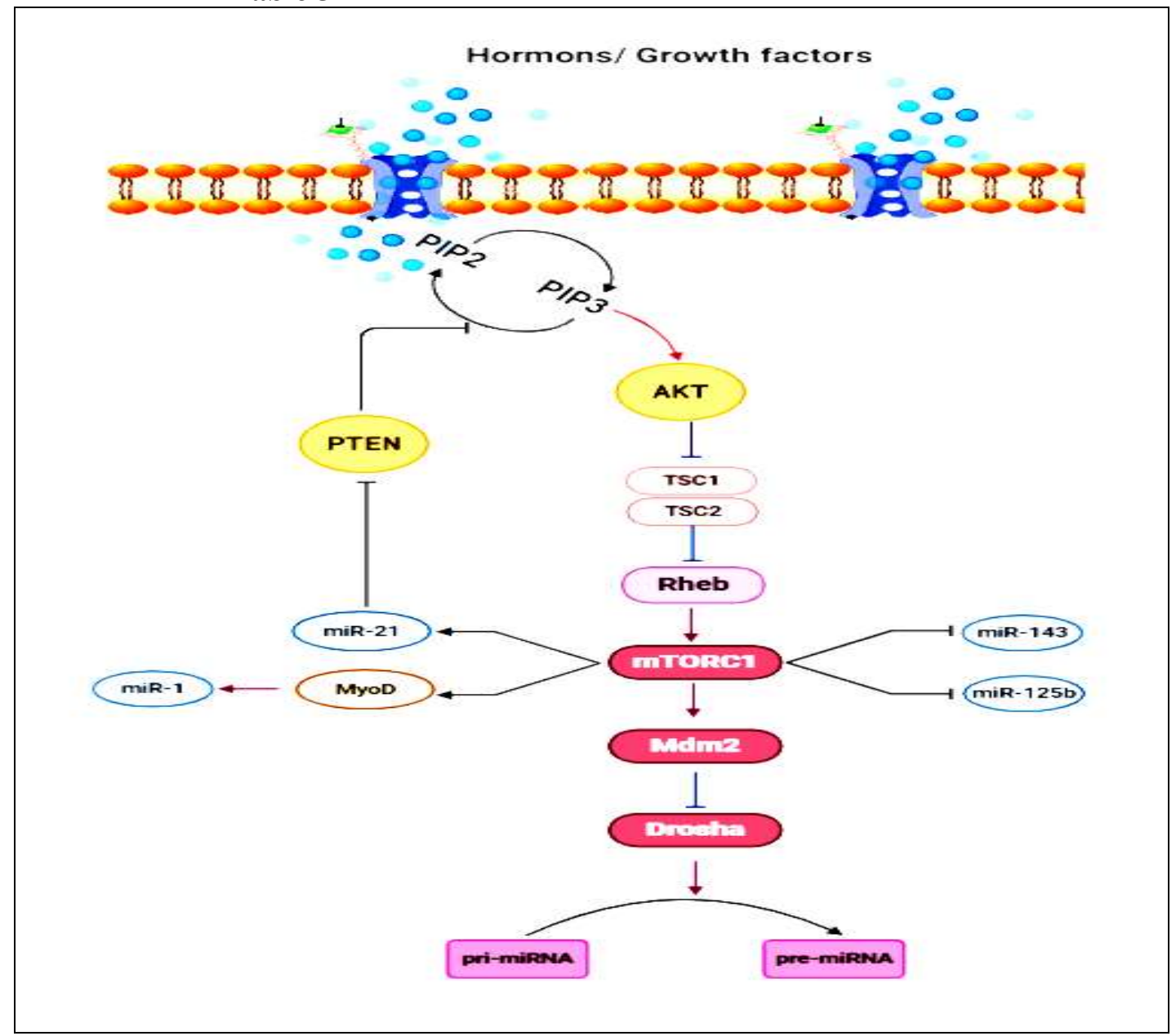

Figure 2: mTOR route Controls the Expression Levels of some miRNAs

[Through Mdm2-dependent pathway and Dorsha decaying, mTOR governs some miRNAs synthesis.] 
Table 5: miRNAs List targeting various mTOR Pathway Signals

\begin{tabular}{|c|c|c|c|}
\hline miRNAs List & $\begin{array}{l}\text { Targeted } \\
\text { Gene(s) }\end{array}$ & Cancer Type & Effect \\
\hline miR-7[145] & $\begin{array}{l}\mathrm{AKT} \\
\mathrm{PI}_{3} \mathrm{~K}\end{array}$ & $\begin{array}{l}\text { HCC } \\
\text { Adrenocortical }\end{array}$ & $\begin{array}{l}\text { Proliferation } \\
\text { Invasion }\end{array}$ \\
\hline $\begin{array}{l}\text { miR-99 } \\
\text { family[146]'[147]'[148]'[149] } \\
\text { (miR-99a, miR-99b, miR-100) }\end{array}$ & $\begin{array}{l}\text { mTOR } \\
\text { AKT }\end{array}$ & $\begin{array}{l}\text { Endometrial } \\
\text { NSCLC, } \\
\text { Cervical } \\
\text { Breast } \\
\text { Pancreatic } \\
\text { HCC, } \\
\text { Esophageal, } \\
\text { Bladder }\end{array}$ & $\begin{array}{l}\text { Proliferation, } \\
\text { Invasion, } \\
\text { Apoptosis, } \\
\text { Cell Cycle, } \\
\text { Autophagy, } \\
\text { Tumor Formation }\end{array}$ \\
\hline miR-101[143] & $\begin{array}{l}\text { EZH2 } \\
\text { mTOR }\end{array}$ & $\begin{array}{l}\text { HCC, } \\
\text { Osteosarcoma }\end{array}$ & $\begin{array}{l}\text { Proliferation, Invasion, } \\
\text { Cell Cycle }\end{array}$ \\
\hline miR-122[150] & $\mathrm{PI}_{3} \mathrm{~K}$ & Breast & Proliferation \\
\hline miR-149[143] & $\begin{array}{l}\text { mTOR } \\
\text { AKT }\end{array}$ & $\begin{array}{l}\text { Cervical } \\
\text { Glioma, HCC }\end{array}$ & Proliferation \\
\hline miR-193a-3p/5 $[151]^{p}[152]^{\prime}[153]$ & $\begin{array}{l}\text { mTOR } \\
\mathrm{Pl}_{3} \mathrm{~K}\end{array}$ & NSCLC & $\begin{array}{l}\text { Proliferation, Migra- } \\
\text { tion, } \\
\text { Epithelial Mesenchy- } \\
\text { mal Transition (EMT) } \\
\end{array}$ \\
\hline miR-204[154] & mTOR & NSCLC & Metastasis \\
\hline miR-155[143] & $\begin{array}{l}\text { AKT } \\
\text { S6K1 } \\
\text { Rictor }\end{array}$ & $\begin{array}{l}\text { Cervical } \\
\text { Nasopharyngeal } \\
\text { Breast } \\
\end{array}$ & Autophagy \\
\hline miR-214[155]'[156] & AKT & Renal & Proliferation \\
\hline miR-218[157],[158]'[159] & $\begin{array}{l}\mathrm{PI}_{3} \mathrm{~K} \\
\mathrm{AKT} \\
\text { mTOR } \\
\text { mTOR }\end{array}$ & $\begin{array}{l}\text { Colorectal } \\
\text { OSCC } \\
\text { Cervical } \\
\text { HCC }\end{array}$ & $\begin{array}{l}\text { Tumorigenesis Pro- } \\
\text { gression, } \\
\text { Invasion, Migration } \\
\text { Metastasis }\end{array}$ \\
\hline miR-199a[161] & mTOR & $\begin{array}{l}\text { Glioma, } \\
\text { Endometrial } \\
\text { HCC }\end{array}$ & Proliferation \\
\hline miR-22[162] & mTOR & Suprarenal epithelioma & Metastasis \\
\hline miR-93[163]'[164],'[165]'[166] & PTEN & $\begin{array}{l}\text { Osteosarcomas, } \\
\text { Ovarian } \\
\text { Breast }\end{array}$ & $\begin{array}{l}\text { Proliferation, Migra- } \\
\text { tion, Invasion, } \\
\text { Inhibiting Apoptosis }\end{array}$ \\
\hline miR-532-5p[167] & mTOR & Gastric & $\begin{array}{l}\text { Proliferation, Metasta- } \\
\text { sis }\end{array}$ \\
\hline miR-451[168] & $\begin{array}{l}\text { mTOR } \\
\text { AMPK }\end{array}$ & Colon & $\begin{array}{l}\text { Proliferation, } \\
\text { Migration }\end{array}$ \\
\hline miR-205[169] & PTEN & NSCLC & $\begin{array}{l}\text { Proliferation, } \\
\text { genesis }\end{array}$ \\
\hline miR-96[170]'[171]'[172] & $\begin{array}{l}\text { mTOR } \\
\text { PRAS40 }\end{array}$ & $\begin{array}{l}\text { Prostatic } \\
\text { Breast } \\
\text { Pancreatic }\end{array}$ & $\begin{array}{l}\text { Proliferation, } \\
\text { Metastasis }\end{array}$ \\
\hline miR-634[173] & mTOR & Cervical & $\begin{array}{l}\text { Proliferation, Metasta- } \\
\text { sis, Apoptosis }\end{array}$ \\
\hline miR-21 & TSC & Gastric & Proliferation, \\
\hline
\end{tabular}




\begin{tabular}{llll}
\hline$[174] \cdot[175] \cdot[176],[177],[178],[179]$ & $\begin{array}{l}\text { PTEN } \\
\text { PI3K } \\
\text { PDCD4 }\end{array}$ & $\begin{array}{l}\text { Lymphadenoma, } \\
\text { NSCLC, HCC, } \\
\text { Breast } \\
\text { Pancreatic } \\
\text { Renal }\end{array}$ & Cell cycle \\
\hline miR-1271[180] & mTOR & Gastric & $\begin{array}{l}\text { Proliferation, Apopto- } \\
\text { sis }\end{array}$ \\
\hline miR-125b[181] & mTOR & $\begin{array}{l}\text { Sarcoma, } \\
\text { Small cell osteosarcoma }\end{array}$ & $\begin{array}{l}\text { Proliferation, Metasta- } \\
\text { sis, } \\
\text { Cell Cycle, Apoptosis }\end{array}$ \\
\hline
\end{tabular}

\subsubsection{MiRNAs and Multidrug Resistance in Cancer Therapy}

Over decades, the significant clinical obstacle to successful cancer treatment is multidrug resistance (MDR), arising from ATP binding cassette (ABC) drug transporter(s) dysregulation, apoptosis or autophagy machinery surrender, redox homeostasis imbalance, as well as drug dysregulated metabolism and drug target alterations[182]. Several manuscripts addressed miRNAs role in MDR[183],[184]'[185] Therefore, miRNAs might be potential targets for preventing chemotherapy MDR.

Differences in miRNAs expression pattern in drug-resistant cancer cells relative to drug-sensitive cells[182], have been reported. miRNAs list to regulate MDR by stressing on a specific cellular-signaling pathway or transporters is summarized in Table 6.

Table 6: miRNAs List involved in Multi Drug Resistance highlighting their regulatory function(s) and the MDR targets

\begin{tabular}{|c|c|c|}
\hline Regulation of & Target & miRNAs List \\
\hline \multirow[t]{12}{*}{ MDR Transporters } & ABCB1/MDR1 & $\begin{array}{l}\text { miR-302c, miR-3664[186], } \operatorname{miR-873[187],~miR-381,~} \\
\text { miR-495, miR-223, miR-203a, miR-200c[188], } \\
\text { miR-508-5p[189] }\end{array}$ \\
\hline & ABCG2/BCRP & $\begin{array}{l}\text { miR-328, miR-519, miR-520, miR-181a, miR-487a, } \\
\text { miR-519c, miR-212[190] }\end{array}$ \\
\hline & ABCC1/MRP1 & miR-326, miR-1291, miR-508-5p[191] \\
\hline & p53 & miR-125a/b, miR-140[192], miR-122, miR-34 \\
\hline & CDK6 & $\begin{array}{l}\text { miR-34a, miR-139-5p[193], miR-143[194], miR-503, } \\
\text { miR-1271 }\end{array}$ \\
\hline & BCL2 & $\begin{array}{l}\text { miR-15b, miR-16, miR-21, miR-497, miR-200bc/429, } \\
\text { miR-1915, miR-214, miR-195[195], miR-205 }\end{array}$ \\
\hline & BCL-XL & miR-574-3p \\
\hline & MCL-1 & $\operatorname{miR}-101[196]$ \\
\hline & BIM & $\operatorname{miR}-494$ \\
\hline & BAX & $\operatorname{miR}-365$ \\
\hline & Caspase-3 & $\operatorname{miR}-30 \mathrm{~b} / \mathrm{c}, \mathrm{miR}-21$ \\
\hline & PTEN & $\begin{array}{l}\text { miR-21, miR-22, miR-221, miR-214, miR-19a/b, miR- } \\
\text { NA-17-5p, miR-222[197] }\end{array}$ \\
\hline
\end{tabular}




\begin{tabular}{|c|c|c|}
\hline Autophagy Induction & Beclin-1\&ATG5 & $\begin{array}{l}\text { miR-30a, miR-30d/e, miR-155, miR-15a[198], miR-16[199], } \\
\text { miR-200b[191], miR-181a[200] }\end{array}$ \\
\hline \multirow{4}{*}{$\begin{array}{l}\text { Anti-cancer Drug Me- } \\
\text { tabolism Modulation }\end{array}$} & CYP1B1 & $\operatorname{miR-27b}[201]$ \\
\hline & CYP1A1 & miR-892a, miR-130b[202] \\
\hline & CYP2J2 & let-7b[182] \\
\hline & CYP3A4 & miR-148a, miR-27b \\
\hline \multirow{5}{*}{$\begin{array}{l}\text { Drug Targets Modula- } \\
\text { tion[182] }\end{array}$} & TS enzyme & miR-192, miR-215 \\
\hline & DPD enzyme & miR-27a, miR-27b, miR-134, miR-582-5p \\
\hline & RRM2 & miR-211, let-7 \\
\hline & MMR proteins & miR-21, miR-155 \\
\hline & BRCA1 & miR-182, miR-9, miR-218[203], miR-638[204] \\
\hline \multirow{2}{*}{$\begin{array}{l}\text { GSH \& GSH-dependent } \\
\text { Enzymes }\end{array}$} & GSH & miRNA-27a[182] \\
\hline & GST & miR-513a-3p, miR-133b[205] \\
\hline
\end{tabular}

\section{Conclusion}

7.1. One abundant class of ncRNAs is miRs. MiRs are involved in the pathogenesis as well as detection of various NCDs, including different cancer types. Moreover, miRNAs are linked to mTOR signaling pathway, a fundamental pathway of MDR and/or carcinogenesis. Current evidence indicates that in most diseases, including the NCDs, miRNAs and mTOR binding do happen.

\subsection{Recommendations}

Being ideal biomarkers for predicting chemotherapy response, miRs would be possible goals for future drug design to solve MDR. Additionally, combining miRNAs detection together with the mTOR signaling route components, being related to SNPs, would draw the complete picture concerning miRNAs as viable targets for evaluating and prognosticating NCDs.

\section{Author Contributions:}

Mahmoud MM.; Data curation, Original draft preparation and Rewriting, Sanad EF.; Rewriting and Reviewing, Hamdy NM.; Conceptualization, Supervision, Editing, Rewriting, Reviewing

9. Funding: This research received no external funding

10. Conflicts of Interest: The authors declare no conflicts of interest

\section{List of abbreviations}

\begin{tabular}{llll}
\hline ABCB1 & ATP Binding Cassette Subfamily B Member 1 & MRE & MiRNA response elements \\
ABCC1 & ATP Binding Cassette Subfamily C Member 1 & MRP1 & Multidrug resistance-associated protein 1 \\
ABCG & ATP binding cassette super-family G member & mTOR & Mechanistic target of rapamycin \\
AGO & Argonaute & NCDs & Non communicable diseases \\
AMI & Acute myocardial infarction & ncRNAs & Noncoding RNAs \\
AMPK & Adenosine-5-monophosphate-activated protein & NSCLC & Non small-cell lung carcinoma \\
& kinase & ORF & Open reading frame \\
ATG5 & Autophagy related 5 & OncoomiR & Oncogenic miRNA \\
BCL- & B-cell lymphoma-extra large & & \\
XL & & & \\
\hline
\end{tabular}




\begin{tabular}{|c|c|c|c|}
\hline BCL2 & B-cell lymphoma 2 & PD & Parkinson's Disease \\
\hline BCRP & Breast cancer resistant protein & PDCD4 & Proapoptotic factors programmed cell death 4 \\
\hline CDK6 & Cyclin-dependent kinase 6 & PI3K & Phosphoinositide 3- kinase \\
\hline CRC & Colorectal cancer & piRNA & Piwi-interacting RNAs \\
\hline CYP & Cytochrome P450 & PPAR $\gamma$ & Peroxisome Proliferator-activated Receptor $\gamma$ \\
\hline CVD & Cardiovascular diseases & & \\
\hline DCP & De-capping protein & Pre-miRNAs & Precursor-miRNAs \\
\hline DGCR8 & $\begin{array}{l}\text { Drosha-DiGeorge syndrome-critical region } \\
\text { gene } 8\end{array}$ & Pri-miRNAs & Primary miRNAs \\
\hline DPD & Dihydropyrimidine dehydrogenase & PTEN & Phosphatase and tensin homolog \\
\hline dsRNA & Double stranded RNAs & Rictor & Rapamycin-insensitive companion of mTOR \\
\hline EDC4 & Enhancer of de-capping 4 & RISCs & RNA-induced silencing complex \\
\hline eIF4G & Eukaryotic initiation factor 4 & S6K1 & Ribosomal protein S6 kinase beta 1 \\
\hline ERK & Extracellular signal-regulated kinase & shRNAs & Short heterogenous RNAs \\
\hline GSH & Glutathione & siRNA & Small interfering RNA \\
\hline GST & Glutathione S-transferases & snoRNAs & Small nucleolar RNAs \\
\hline HCC & Hepatocellular carcinoma & snRNAs & Small nuclear RNAs \\
\hline МАPK & Mitogen-activated protein kinase & TS & Thymidylate synthase \\
\hline MDR & Multidrug resistance & UTR & Untranslated Region \\
\hline
\end{tabular}

\section{References}

1. Feinberg, M.W.; Moore, K.J. MicroRNA Regulation of Atherosclerosis. Circ. Res. 2016, 118, 703-720 https://doi.org/10.1161/CIRCRESAHA.115.306300.

2. Spadafora, C. A LINE-1-Encoded Reverse Transcriptase-Dependent Regulatory Mechanism Is Active in Embryogenesis and Tumorigenesis. Ann NY Acad Sci 2015, 1341, 164-171.

3. Wang, J.; Chen, J.; Sen, S. MicroRNA as Biomarkers and Diagnostics. J. Cell. Physiol. 2016, 231, 25-30 https://doi.org/10.1002/jcp.25056.

4. Hombach, S.; Kretz, M. Non-coding RNAs: Classification, Biology and Functioning. In Non-coding RNAs in colorectal cancer; Springer, 2016; pp. 3-17 https://doi.org/10.1007/978-3-319-42059-2_1.

5. Hao, C.; Yang, S.; Xu, W.; Shen, J.K.; Ye, S.; Liu, X.; Dong, Z.; Xiao, B.; Feng, Y. MiR-708 Promotes Steroid-Induced Osteonecrosis of Femoral Head, Suppresses Osteogenic Differentiation by Targeting SMAD3. Sci. Rep. 2016, 6, 22599 https://doi.org/10.1038/srep22599.

6. O'Brien, J.; Hayder, H.; Zayed, Y.; Peng, C. Overview of MicroRNA Biogenesis, Mechanisms of Actions, and Circulation. Front. Endocrinol. (Lausanne). 2018, 9, 402 https://doi.org/10.3389/fendo.2018.00402.

7. Catalanotto, C.; Cogoni, C.; Zardo, G. MicroRNA in Control of Gene Expression: An Overview of Nuclear Functions. Int. J. Mol. Sci. 2016, 17, 1712 https://doi.org/10.3390/ijms17101712.

8. de Rie, D.; Abugessaisa, I.; Alam, T.; Arner, E.; Arner, P.; Ashoor, H.; Åström, G.; Babina, M.; Bertin, N.; Burroughs, A.M.; et al. An Integrated Expression Atlas of MiRNAs and Their Promoters in Human and Mouse. Nat. Biotechnol. 2017, 35, 872-878 https://doi.org/10.1038/nbt.3947.

9. Wang, J.; Samuels, D.C.; Zhao, S.; Xiang, Y.; Zhao, Y.-Y.; Guo, Y. Current Research on Non-Coding Ribonucleic Acid (RNA). 
Genes (Basel). 2017, 8, 366 https://doi.org/10.3390/genes8120366.

10. Kai, K.; Dittmar, R.L.; Sen, S. Secretory MicroRNAs as Biomarkers of Cancer. Semin. Cell Dev. Biol. 2018, 78, 22-36 https://doi.org/10.1016/j.semcdb.2017.12.011.

11. Armand-Labit, V.; Pradines, A. Circulating Cell-Free MicroRNAs as Clinical Cancer Biomarkers. Biomol. Concepts 2017, 8, 61-81.

12. ElKhouly, A.M.; Youness, R.A.A.; Gad, M.Z.Z. MicroRNA-486-5p and MicroRNA-486-3p: Multifaceted Pleiotropic Mediators in Oncological and Non-Oncological Conditions. Non-coding RNA Res. 2020, 5, 11-21 https://doi.org/10.1016/j.ncrna.2020.01.001.

13. Condrat, C.E.; Thompson, D.C.; Barbu, M.G.; Bugnar, O.L.; Boboc, A.; Cretoiu, D.; Suciu, N.; Cretoiu, S.M.; Voinea, S.C. MiRNAs as Biomarkers in Disease: Latest Findings Regarding Their Role in Diagnosis and Prognosis. Cells 2020, 9 , 276 https://doi.org/10.3390/cells9020276.

14. Vishnoi, A.; Rani, S. MiRNA Biogenesis and Regulation of Diseases: An Overview. In MicroRNA Profiling; Springer, 2017; pp. 1-10 https://doi.org/10.1007/978-1-4939-6524-3 1.

15. Oliveto, S.; Mancino, M.; Manfrini, N.; Biffo, S. Role of MicroRNAs in Translation Regulation and Cancer. World J. Biol. Chem. 2017, 8, 45 https://doi.org/10.4331/wjbc.v8.i1.45.

16. Alarcón, C.R.; Lee, H.; Goodarzi, H.; Halberg, N.; Tavazoie, S.F. N 6-Methyladenosine Marks Primary MicroRNAs for Processing. Nature 2015, 519, 482-485.

17. Kim, Y.-K.; Kim, B.; Kim, V.N. Re-Evaluation of the Roles of DROSHA, Exportin 5 , and DICER in MicroRNA Biogenesis. Proc. Natl. Acad. Sci. 2016, 113, E1881-E1889 https://doi.org/10.1073/pnas.1602532113.

18. Hansen, T.B.; Venø, M.T.; Jensen, T.I.; Schaefer, A.; Damgaard, C.K.; Kjems, J. Argonaute-Associated Short Introns Are a Novel Class of Gene Regulators. Nat. Commun. 2016, 7, 11538 https://doi.org/10.1038/ncomms11538.

19. Hammond, S.M. An Overview of MicroRNAs. Adv. Drug Deliv. Rev. 2015, 87, 3-14 https://doi.org/10.1016/j.addr.2015.05.001.

20. Seok, H.; Ham, J.; Jang, E.-S.; Chi, S.W. MicroRNA Target Recognition: Insights from Transcriptome-Wide Non-Canonical Interactions. Mol. Cells 2016, 39, 375-381 https://doi.org/10.14348/molcells.2016.0013.

21. Pisarello, M.J.L.; Loarca, L.; Ivanics, T.; Morton, L.; LaRusso, N. MicroRNAs in the Cholangiopathies: Pathogenesis, Diagnosis, and Treatment. J. Clin. Med. 2015, 4, 1688-1712 https://doi.org/10.3390/jcm4091688.

22. Issler, O.; Chen, A. Determining the Role of MicroRNAs in Psychiatric Disorders. Nat. Rev. Neurosci. 2015, 16, 201-212 https://doi.org/10.1038/nrn3879.

23. Bracken, C.P.; Scott, H.S.; Goodall, G.J. A Network-Biology Perspective of MicroRNA Function and Dysfunction in Cancer. Nat. Rev. Genet. 2016, 17, 719-732 https://doi.org/10.1038/nrg.2016.134.

24. Iwakawa, H.; Tomari, Y. The Functions of MicroRNAs: MRNA Decay and Translational Repression. Trends Cell Biol. 2015, 25, 651-665 https://doi.org/10.1016/j.tcb.2015.07.011.

25. Khan, S.; Ayub, H.; Khan, T.; Wahid, F. MicroRNA Biogenesis, Gene Silencing Mechanisms and Role in Breast, Ovarian and Prostate Cancer. Biochimie 2019, 167, 12-24 https://doi.org/10.1016/j.biochi.2019.09.001.

26. Mohammadi, A.; Mansoori, B.; Baradaran, B. The Role of MicroRNAs in Colorectal Cancer. Biomed. Pharmacother. 2016, 84, 705-713 https://doi.org/10.1016/j.biopha.2016.09.099.

27. Arner, P.; Kulyté, A. MicroRNA Regulatory Networks in Human Adipose Tissue and Obesity. Nat. Rev. Endocrinol. 2015, 11, 276-288 https://doi.org/10.1038/nrendo.2015.25. 
28. Iacomino, G.; Siani, A. Role of MicroRNAs in Obesity and Obesity-Related Diseases. Genes Nutr. 2017, 12, 23 https://doi.org/10.1186/s12263-017-0577-z.

29. Hamam, D.; Ali, D.; Kassem, M.; Aldahmash, A.; Alajez, N.M. MicroRNAs as Regulators of Adipogenic Differentiation of Mesenchymal Stem Cells. Stem Cells Dev. 2015, 24, 417-425 https://doi.org/10.1089/scd.2014.0331.

30. Das, S.; Mohamed, I.N.; Teoh, S.L.; Thevaraj, T.; Ku Ahmad Nasir, K.N.; Zawawi, A.; Salim, H.H.; Zhou, D.K. Micro-RNA and the Features of Metabolic Syndrome: A Narrative Review. Mini-Reviews Med. Chem. 2020, 20, 626-635 https://doi.org/10.2174/1389557520666200122124445.

31. He, Y.; Ding, Y.; Liang, B.; Lin, J.; Kim, T.-K.; Yu, H.; Hang, H.; Wang, K. A Systematic Study of Dysregulated MicroRNA in Type 2 Diabetes Mellitus. Int. J. Mol. Sci. 2017, 18, 456 https://doi.org/10.3390/ijms18030456.

32. Barutta, F.; Bellini, S.; Mastrocola, R.; Bruno, G.; Gruden, G. MicroRNA and Microvascular Complications of Diabetes. Int. J. Endocrinol. 2018, 2018, 1-20 https://doi.org/10.1155/2018/6890501.

33. Schulte, C.; Karakas, M.; Zeller, T. MicroRNAs in Cardiovascular Disease - Clinical Application. Clin. Chem. Lab. Med. 2017, 55, 687-704 https://doi.org/10.1515/cclm-2016-0576.

34. Liu, X.; Fan, Z.; Zhao, T.; Cao, W.; Zhang, L.; Li, H.; Xie, Q.; Tian, Y.; Wang, B. Plasma MiR-1, MiR-208, MiR-499 as Potential Predictive Biomarkers for Acute Myocardial Infarction: An Independent Study of Han Population. Exp. Gerontol. 2015, 72, 230-238 https://doi.org/10.1016/j.exger.2015.10.011.

35. Volný, O.; Kašičková, L.; Coufalová, D.; Cimflová, P.; Novák, J. microRNAs in Cerebrovascular Disease. In Advances in experimental medicine and biology; United States, 2015; Vol. 888, pp. 155-195 https://doi.org/10.1007/978-3-319-22671-2 9.

36. Vasudeva, K.; Munshi, A. MiRNA Dysregulation in Ischaemic Stroke: Focus on Diagnosis, Prognosis, Therapeutic and Protective Biomarkers. Eur. J. Neurosci. 2020, 52, 3610-3627 https://doi.org/10.1111/ejn.14695.

37. Youness, R.A.; Gad, M.Z. Long Non-Coding RNAs: Functional Regulatory Players in Breast Cancer. Non-coding RNA Res. 2019, 4, 36-44 https://doi.org/10.1016/j.ncrna.2019.01.003.

38. Ahmed Youness, R.; Amr Assal, R.; Mohamed Ezzat, S.; Zakaria Gad, M.; Abdel Motaal, A. A Methoxylated Quercetin Glycoside Harnesses HCC Tumor Progression in a TP53/MiR-15/MiR-16 Dependent Manner. Nat. Prod. Res. 2020, 34, 1475-1480 https://doi.org/10.1080/14786419.2018.1509326.

39. Shaalan, Y.M.; Handoussa, H.; Youness, R.A.; Assal, R.A.; El-Khatib, A.H.; Linscheid, M.W.; El Tayebi, H.M.; Abdelaziz, A.I. Destabilizing the Interplay between MiR-1275 and IGF2BPs by Tamarix Articulata and Quercetin in Hepatocellular Carcinoma. Nat. Prod. Res. 2018, 32, 2217-2220 https://doi.org/10.1080/14786419.2017.1366478.

40. Rahmoon, M.A.; Youness, R.A.; Gomaa, A.I.; Hamza, M.T.; Waked, I.; El Tayebi, H.M.; Abdelaziz, A.I. MiR-615-5p Depresses Natural Killer Cells Cytotoxicity through Repressing IGF-1R in Hepatocellular Carcinoma Patients. Growth Factors 2017, 35, 76-87 https://doi.org/10.1080/08977194.2017.1354859.

41. Frixa, T.; Donzelli, S.; Blandino, G. Oncogenic MicroRNAs: Key Players in Malignant Transformation. Cancers (Basel). 2015, 7, 2466-2485 https://doi.org/10.3390/cancers7040904.

42. Li, G.; Ning, C.; Ma, Y.; Jin, L.; Tang, Q.; Li, X.; Li, M.; Liu, H. MiR-26b Promotes 3T3-L1 Adipocyte Differentiation Through Targeting PTEN. DNA Cell Biol. 2017, 36, 672-681 https://doi.org/10.1089/dna.2017.3712.

43. Li, M.; Liu, Z.; Zhang, Z.; Liu, G.; Sun, S.; Sun, C. MiR-103 Promotes 3T3-L1 Cell Adipogenesis through AKT/MTOR Signal Pathway with Its Target Being MEF2D. Biol. Chem. 2015, 396, 235-244 https://doi.org/10.1515/hsz-2014-0241.

44. Shi, C.; Zhang, M.; Tong, M.; Yang, L.; Pang, L.; Chen, L.; Xu, G.; Chi, X.; Hong, Q.; Ni, Y.; et al. MiR-148a Is Associated with Obesity and Modulates Adipocyte Differentiation of Mesenchymal Stem Cells through Wnt Signaling. Sci. Rep. 2015, 5, 9930 https://doi.org/10.1038/srep09930. 
45. Cioffi, M.; Vallespinos-Serrano, M.; Trabulo, S.M.; Fernandez-Marcos, P.J.; Firment, A.N.; Vazquez, B.N.; Vieira, C.R.; Mulero, F.; Camara, J.A.; Cronin, U.P.; et al. MiR-93 Controls Adiposity via Inhibition of Sirt7 and Tbx3. Cell Rep. 2015, 12, 1594-1605 https://doi.org/10.1016/j.celrep.2015.08.006.

46. Belarbi, Y.; Mejhert, N.; Lorente-Cebrián, S.; Dahlman, I.; Arner, P.; Rydén, M.; Kulyté, A.; Kulyte, A. MicroRNA-193b Controls Adiponectin Production in Human White Adipose Tissue. J. Clin. Endocrinol. Metab. 2015, 100, E1084-E1088 https://doi.org/10.1210/jc.2015-1530.

47. Tattikota, S.G.; Rathjen, T.; Hausser, J.; Khedkar, A.; Kabra, U.D.; Pandey, V.; Sury, M.; Wessels, H.-H.; Mollet, I.G.; Eliasson, L.; et al. MiR-184 Regulates Pancreatic $\beta$-Cell Function According to Glucose Metabolism. J. Biol. Chem. 2015, 290, 20284-20294 https://doi.org/10.1074/jbc.M115.658625.

48. Coskun, E.; Ercin, M.; Gezginci-Oktayoglu, S. The Role of Epigenetic Regulation and Pluripotency-Related MicroRNAs in Differentiation of Pancreatic Stem Cells to Beta Cells. J. Cell. Biochem. 2018, 119, 455-467 https://doi.org/10.1002/jcb.26203.

49. Samandari, N.; Mirza, A.H.; Nielsen, L.B.; Kaur, S.; Hougaard, P.; Fredheim, S.; Mortensen, H.B.; Pociot, F. Circulating MicroRNA Levels Predict Residual Beta Cell Function and Glycaemic Control in Children with Type 1 Diabetes Mellitus. Diabetologia 2017, 60, 354-363 https://doi.org/10.1007/s00125-016-4156-4.

50. LaPierre, M.P.; Stoffel, M. MicroRNAs as Stress Regulators in Pancreatic Beta Cells and Diabetes. Mol. Metab. 2017, 6, 1010-1023 https://doi.org/10.1016/j.molmet.2017.06.020.

51. Sebastiani, G.; Valentini, M.; Grieco, G.E.; Ventriglia, G.; Nigi, L.; Mancarella, F.; Pellegrini, S.; Martino, G.; Sordi, V.; Piemonti, L.; et al. MicroRNA Expression Profiles of Human IPSCs Differentiation into Insulin-Producing Cells. Acta Diabetol. 2017, 54, 265-281 https://doi.org/10.1007/s00592-016-0955-9.

52. Bai, C.; Gao, Y.; Li, X.; Wang, K.; Xiong, H.; Shan, Z.; Zhang, P.; Wang, W.; Guan, W.; Ma, Y. MicroRNAs Can Effectively Induce Formation of Insulin-Producing Cells from Mesenchymal Stem Cells. J. Tissue Eng. Regen. Med. 2017, 11, 3457-3468 https://doi.org/10.1002/term.2259.

53. Engelmann, I.; Alidjinou, E.K.; Bertin, A.; Bossu, J.; Villenet, C.; Figeac, M.; Sane, F.; Hober, D. Persistent Coxsackievirus B4 Infection Induces MicroRNA Dysregulation in Human Pancreatic Cells. Cell. Mol. Life Sci. 2017, 74, 3851-3861 https://doi.org/10.1007/s00018-017-2567-0.

54. Vienberg, S.; Geiger, J.; Madsen, S.; Dalgaard, L.T. Micro RNA s in Metabolism. Acta Physiol. 2017, $219,346-361$.

55. Grieco, F.A.; Sebastiani, G.; Juan-Mateu, J.; Villate, O.; Marroqui, L.; Ladrière, L.; Tugay, K.; Regazzi, R.; Bugliani, M.; Marchetti, P.; et al. MicroRNAs MiR-23a-3p, MiR-23b-3p, and MiR-149-5p Regulate the Expression of Proapoptotic BH3-Only Proteins DP5 and PUMA in Human Pancreatic $\beta$-Cells. Diabetes 2017, 66, 100-112 https://doi.org/10.2337/db16-0592.

56. Sims, E.K.; Lakhter, A.J.; Anderson-Baucum, E.; Kono, T.; Tong, X.; Evans-Molina, C. MicroRNA 21 Targets BCL2 MRNA to Increase Apoptosis in Rat and Human Beta Cells. Diabetologia 2017, 60, 1057-1065 https://doi.org/10.1007/s00125-017-4237-z.

57. Anuradha, R.; Saraswati, M.; Kumar, K.G.; Rani, S.H. Apoptosis of Beta Cells in Diabetes Mellitus. DNA Cell Biol. 2014, 33, 743-748 https://doi.org/10.1089/dna.2014.2352.

58. Hubal, M.J.; Nadler, E.P.; Ferrante, S.C.; Barberio, M.D.; Suh, J.-H.J.; Wang, J.; Dohm, G.L.; Pories, W.J.; Mietus-Snyder, M.; Freishtat, R.J.; et al. Circulating Adipocyte-Derived Exosomal MicroRNAs Associated with Decreased Insulin Resistance after Gastric Bypass. Obesity 2017, 25, 102-110 https://doi.org/10.1002/oby.21709.

59. Vivacqua, A.; Marco, P. De; Belfiore, A.; Maggiolini, M.; De Marco, P.; Belfiore, A.; Maggiolini, M. Recent Advances on the Role of MicroRNAs in Both Insulin Resistance and Cancer. Curr. Pharm. Des. 2017, 23, 3658-3666 https://doi.org/10.2174/1381612823666170622105123.

60. Martinez-Sanchez, A.; Nguyen-Tu, M.-S.; Rutter, G.A. DICER Inactivation Identifies Pancreatic $\beta$-Cell “Disallowed” Genes Targeted by MicroRNAs. Mol. Endocrinol. 2015, 29, 1067-1079 https://doi.org/10.1210/me.2015-1059. 
61. Wu, H.; Zhang, T.; Pan, F.; Steer, C.J.; Li, Z.; Chen, X.; Song, G. MicroRNA-206 Prevents Hepatosteatosis and Hyperglycemia by Facilitating Insulin Signaling and Impairing Lipogenesis. J. Hepatol. 2017, 66, 816-824 https://doi.org/10.1016/j.jhep.2016.12.016.

62. Gu, T.T.-T.; Song, L.; Chen, T.-Y.T.; Wang, X.; Zhao, X.-J.X.; Ding, X.-Q.X.; Yang, Y.Y.-Z.; Pan, Y.; Zhang, D.D.-M.; Kong, L.L.-D. Fructose Downregulates MiR-330 to Induce Renal Inflammatory Response and Insulin Signaling Impairment: Attenuation by Morin. Mol. Nutr. Food Res. 2017, 61, 1600760 https://doi.org/10.1002/mnfr.201600760.

63. Lima, T.I.; Araujo, H.N.; Menezes, E.S.; Sponton, C.H.; Araújo, M.B.; Bomfim, L.H.M.M.; Queiroz, A.L.; Passos, M.A.; e Sousa, T.A.; Hirabara, S.M.; et al. Role of MicroRNAs on the Regulation of Mitochondrial Biogenesis and Insulin Signaling in Skeletal Muscle. J. Cell. Physiol. 2017, 232, 958-966 https://doi.org/10.1002/jcp.25645.

64. Wang, Y.U.; Chang, W.; Zhang, Y.; Zhang, L.; Ding, H.; Qi, H.; Xue, S.; Yu, H.; Hu, L.; Liu, D. Circulating MiR-22-5p and MiR-122-5p Are Promising Novel Biomarkers for Diagnosis of Acute Myocardial Infarction. J. Cell. Physiol. 2019, 234, 4778-4786.

65. Potus, F.; Ruffenach, G.; Dahou, A.; Thebault, C.; Breuils-Bonnet, S.; Tremblay, È.; Nadeau, V.; Paradis, R.; Graydon, C.; Wong, R.; et al. Downregulation of MicroRNA-126 Contributes to the Failing Right Ventricle in Pulmonary Arterial Hypertension. Circulation 2015, 132, 932-943 https://doi.org/10.1161/CIRCULATIONAHA.115.016382.

66. Li, Z.; Tao, Y.; Wang, X.; Jiang, P.; Li, J.; Peng, M.; Zhang, X.; Chen, K.; Liu, H.; Zhen, P.; et al. Tumor-Secreted Exosomal MiR-222 Promotes Tumor Progression via Regulating P27 Expression and Re-Localization in Pancreatic Cancer. Cell. Physiol. Biochem. 2018, 51, 610-629 https://doi.org/10.1159/000495281.

67. da Silva, A.M.G.; de Araújo, J.N.G.; de Oliveira, K.M.M.; Novaes, A.E.M.; Lopes, M.B.; de Sousa, J.C.V.; Filho, A.A. de A.; Luchessi, A.D.A.D.; de Rezende, A.A.; Hirata, M.H.M.H.; et al. Circulating MiRNAs in Acute New-Onset Atrial Fibrillation and Their Target MRNA Network. J. Cardiovasc. Electrophysiol. 2018, 29, 1159-1166 https://doi.org/10.1111/jce.13612.

68. Shen, N.-N.; Zhang, C.; Li, Z.; Kong, L.-C.; Wang, X.-H.; Gu, Z.-C.; Wang, J.-L. MicroRNA Expression Signatures of Atrial Fibrillation: The Critical Systematic Review and Bioinformatics Analysis. Exp. Biol. Med. 2020, 245, 42-53 https://doi.org/10.1177/1535370219890303.

69. Hijmans, J.G.; Diehl, K.J.; Bammert, T.D.; Kavlich, P.J.; Lincenberg, G.M.; Greiner, J.J.; Stauffer, B.L.; DeSouza, C.A. Association between Hypertension and Circulating Vascular-Related MicroRNAs. J. Hum. Hypertens. 2018, 32, 440-447 https://doi.org/10.1038/s41371-018-0061-2.

70. Yang, X.; Niu, X.; Xiao, Y.; Lin, K.; Chen, X. MiRNA Expression Profiles in Healthy OSAHS and OSAHS with Arterial Hypertension: Potential Diagnostic and Early Warning Markers. Respir. Res. 2018, 19, 194 https://doi.org/10.1186/s12931-018-0894-9.

71. Dewdney, B.; Trollope, A.; Moxon, J.; Thomas Manapurathe, D.; Biros, E.; Golledge, J.; Manapurathe, D.T.; Biros, E.; Golledge, J. Circulating MicroRNAs as Biomarkers for Acute Ischemic Stroke: A Systematic Review. J. Stroke Cerebrovasc. Dis. 2018, 27, 522-530 https://doi.org/10.1016/j.jstrokecerebrovasdis.2017.09.058.

72. Li, P.; Teng, F.; Gao, F.; Zhang, M.; Wu, J.; Zhang, C. Identification of Circulating MicroRNAs as Potential Biomarkers for Detecting Acute Ischemic Stroke. Cell. Mol. Neurobiol. 2015, 35, 433-447 https://doi.org/10.1007/s10571-014-0139-5.

73. Stary, C.M.; Xu, L.; Sun, X.; Ouyang, Y.-B.; White, R.E.; Leong, J.; Li, J.; Xiong, X.; Giffard, R.G. MicroRNA-200c Contributes to Injury From Transient Focal Cerebral Ischemia by Targeting Reelin. Stroke 2015, 46, 551-556 https://doi.org/10.1161/STROKEAHA.114.007041.

74. Kim, J.-M.; Jung, K.-H.; Chu, K.; Lee, S.K.S.-T.; Ban, J.; Moon, J.; Kim, M.; Lee, S.K.S.-T.; Roh, J.-K. Atherosclerosis-Related Circulating MicroRNAs as a Predictor of Stroke Recurrence. Transl. Stroke Res. 2015, 6, 191-197 https://doi.org/10.1007/s12975-015-0390-1.

75. Dong, H.; Li, J.; Huang, L.; Chen, X.; Li, D.; Wang, T.; Hu, C.; Xu, J.; Zhang, C.C.-Y.C.; Zen, K.; et al. Serum MicroRNA Profiles Serve as Novel Biomarkers for the Diagnosis of Alzheimer's Disease. Dis. Markers 2015, 2015, 1-11 
https://doi.org/10.1155/2015/625659.

76. Cheng, áL; Doecke, J.D.; Sharples, R.A.; Villemagne, V.L.; Fowler, C.J.; Rembach, A.; Martins, R.N.; Rowe, C.C.; Macaulay, S.L.; Masters, C.L.; et al. Prognostic Serum MiRNA Biomarkers Associated with Alzheimer's Disease Shows Concordance with Neuropsychological and Neuroimaging Assessment. Mol. Psychiatry 2015, 20, 1188-1196 https://doi.org/10.1038/mp.2014.127.

77. Ding, H.; Huang, Z.; Chen, M.; Wang, C.; Chen, X.; Chen, J.; Zhang, J. Identification of a Panel of Five Serum MiRNAs as a Biomarker for Parkinson's Disease. Parkinsonism Relat. Disord. 2016, 22, 68-73 https://doi.org/10.1016/j.parkreldis.2015.11.014.

78. Li, N.; Pan, X.; Zhang, J.; Ma, A.; Yang, S.; Ma, J.; Xie, A. Plasma Levels of MiR-137 and MiR-124 Are Associated with Parkinson's Disease but Not with Parkinson's Disease with Depression. Neurol. Sci. 2017, 38, 761-767 https://doi.org/10.1007/s10072-017-2841-9.

79. Schwienbacher, C.; Foco, L.; Picard, A.; Corradi, E.; Serafin, A.; Panzer, J.; Zanigni, S.; Blankenburg, H.; Facheris, M.F.; Giannini, G.; et al. Plasma and White Blood Cells Show Different MiRNA Expression Profiles in Parkinson's Disease. J. Mol. Neurosci. 2017, 62, 244-254 https://doi.org/10.1007/s12031-017-0926-9.

80. Mushtaq, G.; H Greig, N.; Anwar, F.; A Zamzami, M.; Choudhry, H.; M Shaik, M.; A Tamargo, I.; A Kamal, M. MiRNAs as Circulating Biomarkers for Alzheimer's Disease and Parkinson's Disease. Med. Chem. (Los. Angeles). 2016, 12, $217-225$.

81. Wallaert, A.; Van Loocke, W.; Hernandez, L.; Taghon, T.; Speleman, F.; Van Vlierberghe, P. Comprehensive MiRNA Expression Profiling in Human T-Cell Acute Lymphoblastic Leukemia by Small RNA-Sequencing. Sci. Rep. 2017, 7, 7901 https://doi.org/10.1038/s41598-017-08148-x.

82. Pekarsky, Y.; Croce, C.M. Role of MiR-15/16 in CLL. Cell Death Differ. 2015, 22, 6-11 https://doi.org/10.1038/cdd.2014.87.

83. Hironaka-Mitsuhashi, A.; Otsuka, K.; Gailhouste, L.; Sanchez Calle, A.; Kumazaki, M.; Yamamoto, Y.; Fujiwara, Y.; Ochiya, T.; Calle, A.S.; Kumazaki, M.; et al. MiR-1285-5p/ TMEM194A Axis Affects Cell Proliferation in Breast Cancer. Cancer Sci. 2020, 111, 395-405 https://doi.org/10.1111/cas.14287.

84. Jin, F.; Wang, Y.; Li, M.; Zhu, Y.; Liang, H.; Wang, C.; Wang, F.; Zhang, C.-Y.; Zen, K.; Li, L. MiR-26 Enhances Chemosensitivity and Promotes Apoptosis of Hepatocellular Carcinoma Cells through Inhibiting Autophagy. Cell Death Dis. 2018, 8, e2540-e2540 https://doi.org/10.1038/cddis.2016.461.

85. Wang, Y.; Chen, L.; Wu, Z.; Wang, M.; Jin, F.; Wang, N.; Hu, X.; Liu, Z.; Zhang, C.-Y.; Zen, K.; et al. MiR-124-3p Functions as a Tumor Suppressor in Breast Cancer by Targeting CBL. BMC Cancer 2016, 16, 826 https://doi.org/10.1186/s12885-016-2862-4.

86. Hong, B.S.; Ryu, H.S.; Kim, N.; Kim, J.J.-I.; Lee, E.; Moon, H.-G.H.; Kim, K.K.Y.K.H.; Jin, M.-S.; Kwon, N.H.; Kim, S.; et al. Tumor Suppressor MicroRNA-204-5p Regulates Growth, Metastasis, and Immune Microenvironment Remodeling in Breast Cancer. Cancer Res. 2019, 79, canres.0891.2018 https://doi.org/10.1158/0008-5472.CAN-18-0891.

87. Hui, Z.; Yiling, C.; Wenting, Y.; XuQun, H.; ChuanYi, Z.; Hui, L. MiR-491-5p Functions as a Tumor Suppressor by Targeting JMJD2B in ER $\alpha$-Positive Breast Cancer. FEBS Lett. 2015, 589, 812-821 https://doi.org/10.1016/j.febslet.2015.02.014.

88. Yin, K.; Yin, W.; Wang, Y.; Zhou, L.; Liu, Y.; Yang, G.; Wang, J.; Lu, J. MiR-206 Suppresses Epithelial Mesenchymal Transition by Targeting TGF- $\beta$ Signaling in Estrogen Receptor Positive Breast Cancer Cells. Oncotarget 2016, 7, 24537-24548 https://doi.org/10.18632/oncotarget.8233.

89. Ge, S.; Wang, D.; Kong, Q.; Gao, W.; Sun, J. Function of MiR-152 as a Tumor Suppressor in Human Breast Cancer by Targeting PIK3CA. Oncol. Res. Featur. Preclin. Clin. Cancer Ther. 2017, 25, 1363-1371 https://doi.org/10.3727/096504017X14878536973557.

90. Mansoori, B.; Mohammadi, A.; Ghasabi, M.; Shirjang, S.; Dehghan, R.; Montazeri, V.; Holmskov, U.; Kazemi, T.; Duijf, P.; Gjerstorff, M.; et al. MiR-142-3p as Tumor Suppressor MiRNA in the Regulation of Tumorigenicity, Invasion and Migration 
of Human Breast Cancer by Targeting Bach-1 Expression. J. Cell. Physiol. 2019, 234, 9816-9825 https://doi.org/10.1002/jcp.27670.

91. Hu, X.; Wang, Y.; Liang, H.; Fan, Q.; Zhu, R.; Cui, J.; Zhang, W.; Zen, K.; Zhang, C.-Y.; Hou, D.; et al. MiR-23a/b Promote Tumor Growth and Suppress Apoptosis by Targeting PDCD4 in Gastric Cancer. Cell Death Dis. 2017, 8, e3059-e3059 https://doi.org/10.1038/cddis.2017.447.

92. Zhou, L.; Liang, X.; Zhang, L.; Yang, L.; Nagao, N.; Wu, H.; Liu, C.; Lin, S.; Cai, G.; Liu, J. MiR-27a-3p Functions as an Oncogene in Gastric Cancer by Targeting BTG2. Oncotarget 2016, 7, 51943-51954 https://doi.org/10.18632/oncotarget.10460.

93. Wang, J.; Lv, W.; Lin, Z.; Wang, X.; Bu, J.; Su, Y. Hsa_circ_0003159 Inhibits Gastric Cancer Progression by Regulating MiR-223-3p/NDRG1 Axis. Cancer Cell Int. 2020, 20, 57 https://doi.org/10.1186/s12935-020-1119-0.

94. Hou, X.; Zhang, M.; Qiao, H. Diagnostic Significance of MiR-106a in Gastric Cancer. Int. J. Clin. Exp. Pathol. 2015,8 , 13096.

95. Wang, S.; Ma, G.; Zhu, H.; Lv, C.; Chu, H.; Tong, N.; Wu, D.; Qiang, F.; Gong, W.; Zhao, Q.; et al. MiR-107 Regulates Tumor Progression by Targeting NF1 in Gastric Cancer. Sci. Rep. 2016, 6, 36531 https://doi.org/10.1038/srep36531.

96. Lei, C.; Du, F.; Sun, L.; Li, T.; Li, T.; Min, Y.; Nie, A.; Wang, X.; Geng, L.; Lu, Y.; et al. MiR-143 and MiR-145 Inhibit Gastric Cancer Cell Migration and Metastasis by Suppressing MYO6. Cell Death Dis. 2017, 8, e3101-e3101 https://doi.org/10.1038/cddis.2017.493.

97. Fan, Y.; Shi, Y.; Lin, Z.; Huang, X.; Li, J.; Huang, W.; Shen, D.; Zhuang, G.; Liu, W. MiR-9-5p Suppresses Malignant Biological Behaviors of Human Gastric Cancer Cells by Negative Regulation of TNFAIP8L3. Dig. Dis. Sci. 2019, 64, 2823-2829 https://doi.org/10.1007/s10620-019-05626-2.

98. Jafari, N.; Abediankenari, S. MicroRNA-34 Dysregulation in Gastric Cancer and Gastric Cancer Stem Cell. Tumor Biol. 2017, 39, 101042831770165 https://doi.org/10.1177/1010428317701652.

99. Zare, A.; Ahadi, A.; Larki, P.; Omrani, M.D.; Zali, M.R.; Alamdari, N.M.; Ghaedi, H. The Clinical Significance of MiR-335, MiR-124, MiR-218 and MiR-484 Downregulation in Gastric Cancer. Mol. Biol. Rep. 2018, 45, 1587-1595 https://doi.org/10.1007/s11033-018-4278-5.

100. Cao, M.-Q.; You, A.-B.; Zhu, X.-D.; Zhang, W.; Zhang, Y.-Y.; Zhang, S.-Z.; Zhang, K.; Cai, H.; Shi, W.-K.; Li, X.-L.; et al. MiR-182-5p Promotes Hepatocellular Carcinoma Progression by Repressing FOXO3a. J. Hematol. Oncol. 2018, 11, 1-12 https://doi.org/10.1186/s13045-018-0555-y.

101. Moshiri, F.; Salvi, A.; Gramantieri, L.; Sangiovanni, A.; Guerriero, P.; De Petro, G.; Bassi, C.; Lupini, L.; Sattari, A.; Cheung, D.; et al. Circulating MiR-106b-3p, MiR-101-3p and MiR-1246 as Diagnostic Biomarkers of Hepatocellular Carcinoma. Oncotarget 2018, 9, 15350-15364 https://doi.org/10.18632/oncotarget.24601.

102. Lou, Z.; Gong, Y.; Zhou, X.; Hu, G. Low Expression of MiR-199 in Hepatocellular Carcinoma Contributes to Tumor Cell Hyper-proliferation by Negatively Suppressing XBP1. Oncol. Lett. 2018, 16, 6531-6539 https://doi.org/10.3892/ol.2018.9476.

103. Sharma, N.; Baruah, M.M. The MicroRNA Signatures: Aberrantly Expressed MiRNAs in Prostate Cancer. Clin. Transl. Oncol. 2019, 21, 126-144 https://doi.org/10.1007/s12094-018-1910-8.

104. Yin, H.; Sun, Y.; Wang, X.; Park, J.; Zhang, Y.; Li, M.; Yin, J.; Liu, Q.; Wei, M. Progress on the Relationship between MiR-125 Family and Tumorigenesis. Exp. Cell Res. 2015, 339, 252-260 https://doi.org/10.1016/j.yexcr.2015.09.015.

105. Ma, Z.; Luo, Y.; Qiu, M. MiR-143 Induces the Apoptosis of Prostate Cancer LNCap Cells by Suppressing Bcl-2 Expression. Med. Sci. Monit. 2017, 23, 359-365 https://doi.org/10.12659/MSM.899719.

106. Zhou, X.; Lu, Z.; Wang, T.; Huang, Z.; Zhu, W.; Miao, Y. Plasma MiRNAs in Diagnosis and Prognosis of Pancreatic Cancer: A MiRNA Expression Analysis. Gene 2018, 673, 181-193 https://doi.org/10.1016/j.gene.2018.06.037.

107. Pop-Bica, C.; Pintea, S.; Cojocneanu-Petric, R.; Del Sal, G.; Piazza, S.; Wu, Z.-H.; Alencar, A.J.; Lossos, I.S.; Berindan-Neagoe, 
I.; Calin, G.A. MiR-181 Family-Specific Behavior in Different Cancers: A Meta-Analysis View. Cancer Metastasis Rev. 2018, 37, 17-32 https://doi.org/10.1007/s10555-017-9714-9.

108. Ying, X.; Li-ya, Q.; Feng, Z.; Yin, W.; Ji-hong, L. MiR-939 Promotes the Proliferation of Human Ovarian Cancer Cells by Repressing APC2 Expression. Biomed. Pharmacother. 2015, 71, 64-69 https://doi.org/10.1016/j.biopha.2015.02.020.

109. He, L.; Zhu, W.; Chen, Q.; Yuan, Y.; Wang, Y.; Wang, J.; Wu, X. Ovarian Cancer Cell-Secreted Exosomal MiR-205 Promotes Metastasis by Inducing Angiogenesis. Theranostics 2019, 9, 8206.

110. Meng, X.; Joosse, S.A.; Müller, V.; Trillsch, F.; Milde-Langosch, K.; Mahner, S.; Geffken, M.; Pantel, K.; Schwarzenbach, H. Diagnostic and Prognostic Potential of Serum MiR-7, MiR-16, MiR-25, MiR-93, MiR-182, MiR-376a and MiR-429 in Ovarian Cancer Patients. Br. J. Cancer 2015, 113, 1358-1366 https://doi.org/10.1038/bjc.2015.340.

111. Xia, B.; Yang, S.; Liu, T.; Lou, G. MiR-211 Suppresses Epithelial Ovarian Cancer Proliferation and Cell-Cycle Progression by Targeting Cyclin D1 and CDK6. Mol. Cancer 2015, 14, 57 https://doi.org/10.1186/s12943-015-0322-4.

112. Guo, T.; Yu, W.; Lv, S.; Zhang, C.; Tian, Y. MiR-302a Inhibits the Tumorigenicity of Ovarian Cancer Cells by Suppression of SDC1. Int. J. Clin. Exp. Pathol. 2015, 8, 4869.

113. Kim, Y.Y.Y.J.; Kim, Y.Y.Y.J.; Shin, J.H.; Kim, H.; Ku, S.-Y.; Suh, C.S. Variation in MicroRNA Expression Profile of Uterine Leiomyoma with Endometrial Cavity Distortion and Endometrial Cavity Non-Distortion. Int. J. Mol. Sci. 2018, 19, 2524 https://doi.org/10.3390/ijms19092524.

114. Sheikholeslami, S.; Shabani, N.; Shivaee, S.; Tavangar, S.M.; Yeganeh, M.; Hedayati, M.; Lotfi, J.; Gholami, H. Overexpression of Mir-129-1, MiR-146b, Mir-183, and Mir-197 in Follicular Thyroid Carcinoma and Adenoma Tissues. Mol. Cell. Probes 2020, 51, 101536 https://doi.org/10.1016/j.mcp.2020.101536.

115. Ramirez-Moya, J.; Wert-Lamas, L.; Santisteban, P. MicroRNA-146b Promotes PI3K/AKT Pathway Hyperactivation and Thyroid Cancer Progression by Targeting PTEN. Oncogene 2018, 37, 3369-3383.

116. Sui, G.-Q.; Fei, D.; Guo, F.; Zhen, X.; Luo, Q.; Yin, S.; Wang, H. MicroRNA-338-3p Inhibits Thyroid Cancer Progression through Targeting AKT3. Am. J. Cancer Res. 2017, 7, 1177.

117. Wang, P.; Meng, X.; Huang, Y.; Lv, Z.; Liu, J.; Wang, G.; Meng, W.; Xue, S.; Zhang, Q.; Zhang, P.; et al. MicroRNA-497 Inhibits Thyroid Cancer Tumor Growth and Invasion by Suppressing BDNF. Oncotarget 2017, 8, 2825-2834 https://doi.org/10.18632/oncotarget.13747.

118. Falzone, L.; Scola, L.; Zanghì, A.; Biondi, A.; Di Cataldo, A.; Libra, M.; Candido, S. Integrated Analysis of Colorectal Cancer MicroRNA Datasets: Identification of MicroRNAs Associated with Tumor Development. Aging (Albany NY) 2018, 10, 1000 https://doi.org/10.18632/aging.101444.

119. Cirilo, P.D.R.; de Sousa Andrade, L.N.; Corrêa, B.R.S.; Qiao, M.; Furuya, T.K.; Chammas, R.; Penalva, L.O.F. MicroRNA-195 Acts as an Anti-Proliferative MiRNA in Human Melanoma Cells by Targeting Prohibitin 1. BMC Cancer 2017, 17, 750 https://doi.org/10.1186/s12885-017-3721-7.

120. Špaková, I.; Graier, W.F.; Rabajdová, M.; Dubayová, K.; Nagyová, V.; Mareková, M. Hypoxia Factors Suppression Effect on the Energy Metabolism of a Malignant Melanoma Cell SK-MEL-30. Eur Rev Med Pharmacol Sci 2020, 24, 4909-4920 https://doi.org/10.26355/eurrev 202005 21180. PMID: 32432754.

121. Zhou, J.; Xu, D.; Xie, H.; Tang, J.; Liu, R.; Li, J.; Wang, S.; Chen, X.; Su, J.; Zhou, X.; et al. MiR-33a Functions as a Tumor Suppressor in Melanoma by Targeting HIF-1 $\alpha$. Cancer Biol. Ther. 2015, 16, 846-855 https://doi.org/10.1080/15384047.2015.1030545.

122. Wu, S.; Gu, Y.; Huang, Y.; Wong, T.-C.; Ding, H.; Liu, T.; Zhang, Y.; Zhang, X. Novel Biomarkers for Non-Functioning Invasive Pituitary Adenomas Were Identified by Using Analysis of MicroRNAs Expression Profile. Biochem. Genet. 2017, 55, 253-267 https://doi.org/10.1007/s10528-017-9794-9. 
123. Yang, Z.; Zhang, T.; Wang, Q.; Gao, H. Overexpression of MicroRNA-34a Attenuates Proliferation and Induces Apoptosis in Pituitary Adenoma Cells via SOX7. Mol. Ther. - Oncolytics 2018, 10, 40-47 https://doi.org/10.1016/j.omto.2018.07.001.

124. Cai, Q.; Zeng, S.; Dai, X.; Wu, J.; Ma, W. MiR-504 Promotes Tumour Growth and Metastasis in Human Osteosarcoma by Targeting TP53INP1. Oncol. Rep. 2017, 38, 2993-3000 https://doi.org/10.3892/or.2017.5983.

125. Xie, Z.; Xu, J.; Peng, L.; Gao, Y.; Zhao, H.; Qu, Y. MiR-149 Promotes Human Osteocarcinoma Progression via Targeting Bone Morphogenetic Protein 9 (BMP9). Biotechnol. Lett. 2018, 40, 47-55 https://doi.org/10.1007/s10529-017-2445-8.

126. Liu, X.; Peng, H.; Liao, W.; Luo, A.; Cai, M.; He, J.; Zhang, X.; Luo, Z.; Jiang, H.; Xu, L. MiR-181a/b Induce the Growth, Invasion, and Metastasis of Neuroblastoma Cells through Targeting ABI1. Mol. Carcinog. 2018, 57, 1237-1250 https://doi.org/10.1002/mc.22839.

127. Li, Z.; Xu, Z.; Xie, Q.; Gao, W.; Xie, J.; Zhou, L. MiR-1303 Promotes the Proliferation of Neuroblastoma Cell SH-SY5Y by Targeting GSK3 $\beta$ and SFRP1. Biomed. Pharmacother. 2016, 83, 508-513 https://doi.org/10.1016/j.biopha.2016.07.010.

128. Soriano, A.; Masanas, M.; Boloix, A.; Masiá, N.; París-Coderch, L.; Piskareva, O.; Jiménez, C.; Henrich, K.-O.; Roma, J.; Westermann, F.; et al. Functional High-Throughput Screening Reveals MiR-323a-5p and MiR-342-5p as New Tumor-Suppressive MicroRNA for Neuroblastoma. Cell. Mol. Life Sci. 2019, 76, 2231-2243 https://doi.org/10.1007/s00018-019-03041-4.

129. Cheng, X.; Xu, Q.; Zhang, Y.; Shen, M.; Zhang, S.; Mao, F.; Li, B.; Yan, X.; Shi, Z.; Wang, L.; et al. MiR-34a Inhibits Progression of Neuroblastoma by Targeting Autophagy-Related Gene 5. Eur. J. Pharmacol. 2019, 850, 53-63 https://doi.org/10.1016/j.ejphar.2019.01.071.

130. Chava, S.; Reynolds, C.P.; Pathania, A.S.; Gorantla, S.; Poluektova, L.Y.; Coulter, D.W.; Gupta, S.C.; Pandey, M.K.; Challagundla, K.B. MiR-15a-5p, MiR-15b-5p, and MiR-16-5p Inhibit Tumor Progression by Directly Targeting MYCN in Neuroblastoma. Mol. Oncol. 2020, 14, 180-196 https://doi.org/10.1002/1878-0261.12588.

131. Ding, X.; Zhong, T.; Jiang, L.; Huang, J.; Xia, Y.; Hu, R. MiR-25 Enhances Cell Migration and Invasion in Non-Small-Cell Lung Cancer Cells via ERK Signaling Pathway by Inhibiting KLF4. Mol. Med. Rep. 2018, 17, 7005-7016 https://doi.org/10.3892/mmr.2018.8772.

132. Ma, W.; Ma, C.; Zhou, N.; Li, X.; Zhang, Y. Up-Regulation of MiR-328-3p Sensitizes Non-Small Cell Lung Cancer to Radiotherapy. Sci. Rep. 2016, 6, 1-9.

133. Wu, F.; Mo, Q.; Wan, X.; Dan, J.; Hu, H. NEAT1/Hsa-mir-98-5p/MAPK6 Axis Is Involved in Non-Small-cell Lung Cancer Development. J. Cell. Biochem. 2019, 120, 2836-2846 https://doi.org/10.1002/jcb.26442.

134. Liu, Y.; Li, H.; Li, L.H.; Tang, J.B.; Sheng, Y.L. Mir-451 Inhibits Proliferation and Migration of Non-Small Cell Lung Cancer Cells via Targeting LKB1/AMPK. Eur Rev Med Pharmacol Sci 2019, 23, 274-280.

135. Usuba, W.; Urabe, F.; Yamamoto, Y.; Matsuzaki, J.; Sasaki, H.; Ichikawa, M.; Takizawa, S.; Aoki, Y.; Niida, S.; Kato, K.; et al. Circulating MiRNA Panels for Specific and Early Detection in Bladder Cancer. Cancer Sci. 2019, 110, 408-419 https://doi.org/10.1111/cas.13856.

136. Tsai, T.-F.; Lin, J.-F.; Chou, K.-Y.; Lin, Y.-C.; Chen, H.-E.; Hwang, T.I.-S. MiR-99a-5p Acts as Tumor Suppressor via Targeting to MTOR and Enhances RAD001-Induced Apoptosis in Human Urinary Bladder Urothelial Carcinoma Cells. Onco. Targets. Ther. 2018, Volume 11, 239-252 https://doi.org/10.2147/OTT.S114276.

137. Zheng, W.; Liu, Z.; Zhang, W.; Hu, X. MiR-31 Functions as an Oncogene in Cervical Cancer. Arch. Gynecol. Obstet. 2015, 292, 1083-1089 https://doi.org/10.1007/s00404-015-3713-2.

138. Ma, L.; Li, L.-L. MiR-145 Contributes to the Progression of Cervical Carcinoma by Directly Regulating FSCN1. Cell Transplant. 2019, 28, 1299-1305 https://doi.org/10.1177/0963689719861063.

139. Li, N.; Cui, T.; Guo, W.; Wang, D.; Mao, L. MiR-155-5p Accelerates the Metastasis of Cervical Cancer Cell via Targeting 
TP53INP1. Onco. Targets. Ther. 2019, Volume 12, 3181-3196 https://doi.org/10.2147/OTT.S193097.

140. Xue, M.; Qin, X.; Wan, Y.; Wang, S.; Xue, M. MicroRNA-125a-5p Modulates Human Cervical Carcinoma Proliferation and Migration by Targeting ABL2. Drug Des. Devel. Ther. 2015, 10, 71 https://doi.org/10.2147/DDDT.S93104.

141. Geng, D.; Song, X.; Ning, F.; Song, Q.; Yin, H. MiR-34a Inhibits Viability and Invasion of Human Papillomavirus-Positive Cervical Cancer Cells by Targeting E2F3 and Regulating Survivin. Int. J. Gynecol. Cancer 2015, 25, 707-713 https://doi.org/10.1097/IGC.0000000000000399.

142. Xiang, P.; Liu, Y.; Liu, L.; Lin, Q.; Liu, X.; Zhang, H.; Xu, J.; Fang, B. The Biological Function and Clinical Significance of MiR-886-5p in Multiple Myeloma. Acta Haematol. 2019, 142, 208-216 https://doi.org/10.1159/000499620.

143. Zhang, Y.; Huang, B.; Wang, H.-Y.Y.; Chang, A.; Zheng, X.F.S.S. Emerging Role of MicroRNAs in MTOR Signaling. Cell. Mol. Life Sci. 2017, 74, 2613-2625 https://doi.org/10.1007/s00018-017-2485-1.

144. Ye, P.; Liu, Y.Y.; Chen, C.; Tang, F.; Wu, Q.; Wang, X.; Liu, C.-G.; Liu, X.; Liu, R.; Liu, Y.Y.; et al. An MTORC1-Mdm2-Drosha Axis for MiRNA Biogenesis in Response to Glucose- and Amino Acid-Deprivation. Mol. Cell 2015, 57, 708-720 https://doi.org/10.1016/j.molcel.2014.12.034.

145. Glover, A.R.; Zhao, J.T.; Gill, A.J.; Weiss, J.; Mugridge, N.; Kim, E.; Feeney, A.L.; Ip, J.C.; Reid, G.; Clarke, S.; et al. MicroRNA-7 as a Tumor Suppressor and Novel Therapeutic for Adrenocortical Carcinoma. Oncotarget 2015, 6, 36675-36688 https://doi.org/10.18632/oncotarget.5383.

146. Yu, S.S.; Zhang, C.C.; Dong, F.F.; Zhang, Y.Y. MiR-99a Suppresses the Metastasis of Human Non-Small Cell Lung Cancer Cells by Targeting AKT1 Signaling Pathway. J. Cell. Biochem. 2015, 116, 268-276 https://doi.org/10.1002/jcb.24965.

147. Li, W.; Chang, J.; Wang, S.; Liu, X.; Peng, J.; Huang, D.; Sun, M.; Chen, Z.; Zhang, W.; Guo, W.; et al. MiRNA-99b-5p Suppresses Liver Metastasis of Colorectal Cancer by down-Regulating MTOR. Oncotarget 2015, 6, 24448-24462 https://doi.org/10.18632/oncotarget.4423.

148. Zhao, J.; Chen, F.; Zhou, Q.; Pan, W.; Wang, X.; Xu, J.; Ni, L.; Yang, H. Aberrant Expression of MicroRNA-99a and Its Target Gene MTOR Associated with Malignant Progression and Poor Prognosis in Patients with Osteosarcoma. Onco. Targets. Ther. 2016, 9, 1589 https://doi.org/10.2147/OTT.S102421.

149. Li, Y.; Zhang, Z.; Zhang, X.; Lin, Y.; Luo, T.; Xiao, Z.; Zhou, Q. A Dual PI3K/AKT/MTOR Signaling Inhibitor MiR-99a Suppresses Endometrial Carcinoma. Am. J. Transl. Res. 2016, 8, 719.

150. Yang, Y.M.; Lee, C.G.; Koo, J.H.; Kim, T.H.; Lee, J.M.; An, J.; Kim, K.M.; Kim, S.G. Ga12 Overexpressed in Hepatocellular Carcinoma Reduces MicroRNA-122 Expression via HNF4 $\alpha$ Inactivation, Which Causes c-Met Induction. Oncotarget 2015, 6, 19055-19069 https://doi.org/10.18632/oncotarget.3957.

151. Jian, B.; Li, Z.; Xiao, D.; He, G.; Bai, L.; Yang, Q. Downregulation of MicroRNA-193-3p Inhibits Tumor Proliferation Migration and Chemoresistance in Human Gastric Cancer by Regulating PTEN Gene. Tumor Biol. 2016, 37, 8941-8949.

152. Shen, L.; Sun, C.; Li, Y.; Li, X.; Sun, T.; Liu, C.; Zhou, Y.; Du, Z. MicroRNA-199a-3p Suppresses Glioma Cell Proliferation by Regulating the AKT/MTOR Signaling Pathway. Tumor Biol. 2015, 36, 6929-6938 https://doi.org/10.1007/s13277-015-3409-z.

153. Yu, T.; Li, J.; Yan, M.; Liu, L.; Lin, H.; Zhao, F.; Sun, L.; Zhang, Y.; Cui, Y.; Zhang, F.; et al. MicroRNA-193a-3p and -5p Suppress the Metastasis of Human Non-Small-Cell Lung Cancer by Downregulating the ERBB4/PIK3R3/MTOR/S6K2 Signaling Pathway. Oncogene 2015, 34, 413-423 https://doi.org/10.1038/onc.2013.574.

154. Xia, Z.; Liu, F.; Zhang, J.; Liu, L. Decreased Expression of MiRNA-204-5p Contributes to Glioma Progression and Promotes Glioma Cell Growth, Migration and Invasion. PLoS One 2015, 10, e0132399 https://doi.org/10.1371/journal.pone.0132399.

155. Yu, X.; Luo, A.; Liu, Y.; Wang, S.; Li, Y.; Shi, W.; Liu, Z.; Qu, X. MiR-214 Increases the Sensitivity of Breast Cancer Cells to Tamoxifen and Fulvestrant through Inhibition of Autophagy. Mol. Cancer 2015, 14, 208 https://doi.org/10.1186/s12943-015-0480-4. 
156. Das, F.; Dey, N.; Bera, A.; Kasinath, B.S.; Ghosh-Choudhury, N.; Choudhury, G.G. MicroRNA-214 Reduces Insulin-like Growth Factor-1 (IGF-1) Receptor Expression and Downstream MTORC1 Signaling in Renal Carcinoma Cells. J. Biol. Chem. 2016, 291, 14662-14676 https://doi.org/10.1074/jbc.M115.694331.

157. Lu, Y.; Zhang, L.; Waye, M.M.Y.; Fu, W.; Zhang, J. MiR-218 Mediates Tumorigenesis and Metastasis: Perspectives and Implications. Exp. Cell Res. 2015, 334, 173-182 https://doi.org/10.1016/j.yexcr.2015.03.027.

158. ZHANG, X.; Shi, H.; TANG, H.; Fang, Z.; WANG, J.; CUI, S. MiR-218 Inhibits the Invasion and Migration of Colon Cancer Cells by Targeting the PI3K/Akt/MTOR Signaling Pathway. Int. J. Mol. Med. 2015, 35, 1301-1308 https://doi.org/10.3892/ijmm.2015.2126.

159. Tian, H.; HOU, L.; Xiong, Y.-M.; Huang, J.-X.; SHE, Y.-J.; Bi, X.-B.; SONG, X.-R. MiR-218 Suppresses Tumor Growth and Enhances the Chemosensitivity of Esophageal Squamous Cell Carcinoma to Cisplatin. Oncol. Rep. 2015, 33, 981-989 https://doi.org/10.3892/or.2014.3657.

160. Chen, D.; Huang, X.; Lu, S.; Deng, H.; Gan, H.; Huang, R.; Zhang, B. MiRNA-125a Modulates Autophagy of Thyroiditis through PI3K/Akt/MTOR Signaling Pathway. Exp. Ther. Med. 2019, 17, 2465-2472 https://doi.org/10.3892/etm.2019.7256.

161. Callegari, E.; D’Abundo, L.; Guerriero, P.; Simioni, C.; Elamin, B.K.; Russo, M.; Cani, A.; Bassi, C.; Zagatti, B.; Giacomelli, L.; et al. MiR-199a-3p Modulates MTOR and PAK4 Pathways and Inhibits Tumor Growth in a Hepatocellular Carcinoma Transgenic Mouse Model. Mol. Ther. Acids 2018, 11, 485-493 https://doi.org/10.1016/j.omtn.2018.04.002.

162. Meng, C.; Zhao, Z.; Bai, R.; Zhao, W.; Wang, Y.; Xue, H.; Sun, L.; Sun, C.; Feng, W.; Guo, S. MicroRNA-22 Mediates the Cisplatin Resistance of Osteosarcoma Cells by Inhibiting Autophagy via the PI3K/Akt/MTOR Pathway. Oncol. Rep. 2020, 43, 1169-1186 https://doi.org/10.3892/or.2020.7492.

163. Chen, Q.; Qin, R.; Fang, Y.; Li, H. Berberine Sensitizes Human Ovarian Cancer Cells to Cisplatin Through MiR-93/PTEN/Akt Signaling Pathway. Cell. Physiol. Biochem. 2015, 36, 956-965 https://doi.org/10.1159/000430270.

164. Ohta, K.; Hoshino, H.; Wang, J.; Ono, S.; Iida, Y.; Hata, K.; Huang, S.K.; Colquhoun, S.; Hoon, D.S.B. MicroRNA-93 Activates c-Met/PI3K/Akt Pathway Activity in Hepatocellular Carcinoma by Directly Inhibiting PTEN and CDKN1A. Oncotarget 2015, 6, 3211-3224 https://doi.org/10.18632/oncotarget.3085.

165. Jiang, L.; Wang, C.; Lei, F.; Zhang, L.; Zhang, X.; Liu, A.; Wu, G.; Zhu, J.; Song, L. MiR-93 Promotes Cell Proliferation in Gliomas through Activation of PI3K/Akt Signaling Pathway. Oncotarget 2015, 6, 8286-8299 https://doi.org/10.18632/oncotarget.3221.

166. Kawano, M.; Tanaka, K.; Itonaga, I.; Ikeda, S.; Iwasaki, T.; Tsumura, H. MicroRNA-93 Promotes Cell Proliferation via Targeting of PTEN in Osteosarcoma Cells. J. Exp. Clin. Cancer Res. 2015, 34, 76 https://doi.org/10.1186/s13046-015-0192-z.

167. Wang, Y.P.; Liu, J.; Liu, D.; Wang, X.D.; Bian, A.M.; Fang, D.Z.; Hui, X.B. MiR-532-5p Acts as a Tumor Suppressor and Inhibits Glioma Cell Proliferation by Targeting CSF1. Eur. Rev. Med. Pharmacol. Sci 2019, 23, 8964-8970.

168. Du, J.; Liu, S.; He, J.; Liu, X.; Qu, Y.; Yan, W.; Fan, J.; Li, R.; Xi, H.; Fu, W.; et al. MicroRNA-451 Regulates Stemness of Side Population Cells via PI3K/Akt/MTOR Signaling Pathway in Multiple Myeloma. Oncotarget 2015, 6, 14993-15007 https://doi.org/10.18632/oncotarget.3802.

169. Zhuo, Z.; Yu, H. MiR-205 Inhibits Cell Growth by Targeting AKT-MTOR Signaling in Progesterone-Resistant Endometrial Cancer Ishikawa Cells. Oncotarget 2017, 8, 28042-28051 https://doi.org/10.18632/oncotarget.15886.

170. Zhang, W.; Qian, P.; Zhang, X.; Zhang, M.; Wang, H.; Wu, M.; Kong, X.; Tan, S.; Ding, K.; Perry, J.K.; et al. Autocrine/Paracrine Human Growth Hormone-Stimulated MicroRNA 96-182-183 Cluster Promotes Epithelial-Mesenchymal Transition and Invasion in Breast Cancer. J. Biol. Chem. 2015, 290, 13812-13829 https://doi.org/10.1074/jbc.M115.653261.

171. Leung, W.K.C.C.; He, M.; Chan, A.W.H.H.; Law, P.T.Y.Y.; Wong, N. Wnt/ $\beta$-Catenin Activates MiR-183/96/182 Expression in Hepatocellular Carcinoma That Promotes Cell Invasion. Cancer Lett. 2015, 362, 97-105 
https://doi.org/10.1016/j.canlet.2015.03.023.

172. Chong, Z.Z. Targeting PRAS40 for Multiple Diseases. Drug Discov. Today 2016, 21, 1222-1231 https://doi.org/10.1016/j.drudis.2016.04.005.

173. Cong, J.; Liu, R.; Wang, X.; Jiang, H.; Zhang, Y. MiR-634 Decreases Cell Proliferation and Induces Apoptosis by Targeting MTOR Signaling Pathway in Cervical Cancer Cells. Artif. Cells, Nanomedicine, Biotechnol. 2016, 44, 1694-1701 https://doi.org/10.3109/21691401.2015.1080171.

174. Shi, J. Considering Exosomal MiR-21 as a Biomarker for Cancer. J. Clin. Med. 2016, 5, 42.

175. Fragni, M.; Bonini, S.A.; Bettinsoli, P.; Bodei, S.; Generali, D.; Bottini, A.; Spano, P.F.; Memo, M.; Sigala, S. The MiR-21/PTEN/Akt Signaling Pathway Is Involved in the Anti-Tumoral Effects of Zoledronic Acid in Human Breast Cancer Cell Lines. Naunyn. Schmiedebergs. Arch. Pharmacol. 2016, 389, 529-538 https://doi.org/10.1007/s00210-016-1224-8.

176. LI, X.; ZANG, A.; JIA, Y.; Zhang, J.; Fan, W.; FENG, J.; Duan, M.; ZHANG, L.; Huo, R.; Jiao, J.; et al. Triptolide Reduces Proliferation and Enhances Apoptosis of Human Non-Small Cell Lung Cancer Cells through PTEN by Targeting MiR-21. Mol. Med. Rep. 2016, 13, 2763-2768 https://doi.org/10.3892/mmr.2016.4844.

177. Kalogirou, C.; Schäfer, D.; Krebs, M.; Kurz, F.; Schneider, A.; Riedmiller, H.; Kneitz, B.; Vergho, D. Metformin-Derived Growth Inhibition in Renal Cell Carcinoma Depends on MiR-21-Mediated PTEN Expression. Urol. Int. 2016, 96, 106-115 https://doi.org/10.1159/000441011.

178. Chen, J.; Xu, T.; Chen, C. The Critical Roles of MiR-21 in Anti-Cancer Effects of Curcumin. Ann. Transl. Med. 2015, 3.

179. Yu, X.; Li, R.; Shi, W.; Jiang, T.; Wang, Y.; Li, C.; Qu, X. Silencing of MicroRNA-21 Confers the Sensitivity to Tamoxifen and Fulvestrant by Enhancing Autophagic Cell Death through Inhibition of the PI3K-AKT-MTOR Pathway in Breast Cancer Cells. Biomed. Pharmacother. 2016, 77, 37-44 https://doi.org/10.1016/j.biopha.2015.11.005.

180. Xie, F.; Huang, Q.; Liu, C.H.; Lin, X.S.; Liu, Z.; Liu, L.L.; Huang, D.W.; Zhou, H.C. MiR-1271 Negatively Regulates AKT/MTOR Signaling and Promotes Apoptosis via Targeting PDK1 in Pancreatic Cancer. Eur Rev Med Pharmacol Sci 2018, $22,678-686$.

181. Vilquin, P.; Donini, C.F.; Villedieu, M.; Grisard, E.; Corbo, L.; Bachelot, T.; Vendrell, J.A.; Cohen, P.A. MicroRNA-125b Upregulation Confers Aromatase Inhibitor Resistance and Is a Novel Marker of Poor Prognosis in Breast Cancer. Breast Cancer Res. 2015, 17, 13 https://doi.org/10.1186/s13058-015-0515-1.

182. An, X.; Sarmiento, C.; Tan, T.; Zhu, H. Regulation of Multidrug Resistance by MicroRNAs in Anti-Cancer Therapy. Acta Pharm. Sin. B 2017, 7, 38-51 https://doi.org/10.1016/j.apsb.2016.09.002.

183. Geretto, M.; Pulliero, A.; Rosano, C.; Zhabayeva, D.; Bersimbaev, R.; Izzotti, A. Resistance to Cancer Chemotherapeutic Drugs Is Determined by Pivotal MicroRNA Regulators. Am. J. Cancer Res. 2017, 7, 1350-1371.

184. Bach, D.-H.; Hong, J.-Y.; Park, H.J.; Lee, S.K. The Role of Exosomes and MiRNAs in Drug-Resistance of Cancer Cells. Int. J. Cancer 2017, 141, 220-230 https://doi.org/10.1002/ijc.30669.

185. Si, W.; Shen, J.; Zheng, H.; Fan, W. The Role and Mechanisms of Action of MicroRNAs in Cancer Drug Resistance. Clin. Epigenetics 2019, 11, 25 https://doi.org/10.1186/s13148-018-0587-8.

186. Ghanbarian, M.; Afgar, A.; Yadegarazari, R.; Najafi, R.; Teimoori-Toolabi, L. Through Oxaliplatin Resistance Induction in Colorectal Cancer Cells, Increasing ABCB1 Level Accompanies Decreasing Level of MiR-302c-5p, MiR-3664-5p and MiR-129-5p. Biomed. Pharmacother. 2018, 108, 1070-1080 https://doi.org/10.1016/j.biopha.2018.09.112.

187. Wu, D.; Li, X.; Meng, X.-N.; Yan, J.; Zong, Z. MicroRNA-873 Mediates Multidrug Resistance in Ovarian Cancer Cells by Targeting ABCB1. Tumor Biol. 2016, 37, 10499-10506 https://doi.org/10.1007/s13277-016-4944-y.

188. Armada, A.; Gomes, B.C.; Viveiros, M.; Rueff, J.; Rodrigues, A.S. Regulation of ABCB1 Activity by MicroRNA-200c and 
MicroRNA-203a in Breast Cancer Cells: The Quest for MicroRNAs' Involvement in Cancer Drug Resistance. Cancer Drug Resist. 2019, 2, 897-911 https://doi.org/10.20517/cdr.2019.24.

189. Shang, Y.; Feng, B.; Zhou, L.; Ren, G.; Zhang, Z.; Fan, X.; Sun, Y.; Luo, G.; Liang, J.; Wu, K.; et al. The MiR27b-CCNG1-P53-MiR-508-5p Axis Regulates Multidrug Resistance of Gastric Cancer. Oncotarget 2016, 7, 538-549 https://doi.org/10.18632/oncotarget.6374.

190. To, K.K.W.; Leung, W.W.; Ng, S.S.M. Exploiting a Novel MiR-519c-HuR-ABCG2 Regulatory Pathway to Overcome Chemoresistance in Colorectal Cancer. Exp. Cell Res. 2015, 338, 222-231.

191. Pei, K.; Zhu, J.J.; Wang, C.E.; Xie, Q.L.; Guo, J.Y. MicroRNA-185-5p Modulates Chemosensitivity of Human Non-Small Cell Lung Cancer to Cisplatin via Targeting ABCC1. Eur Rev Med Pharmacol Sci 2016, 20, 4697-4704.

192. Liang, S.; Gong, X.; Zhang, G.; Huang, G.; Lu, Y.; Li, Y. MicroRNA-140 Regulates Cell Growth and Invasion in Pancreatic Duct Adenocarcinoma by Targeting IASPP. Acta Biochim. Biophys. Sin. (Shanghai). 2016, 48, 174-181 https://doi.org/10.1093/abbs/gmv127.

193. Li, Q.; Liang, X.; Wang, Y.; Meng, X.; Xu, Y.; Cai, S.; Wang, Z.; Liu, J.; Cai, G. MiR-139-5p Inhibits the Epithelial-Mesenchymal Transition and Enhances the Chemotherapeutic Sensitivity of Colorectal Cancer Cells by Downregulating BCL2. Sci. Rep. 2016, 6, 27157 https://doi.org/10.1038/srep27157.

194. Zhuang, M.; Shi, Q.; Zhang, X.; Ding, Y.Y.; Shan, L.; Shan, X.; Qian, J.; Zhou, X.; Huang, Z.; Zhu, W.; et al. Involvement of MiR-143 in Cisplatin Resistance of Gastric Cancer Cells via Targeting IGF1R and BCL2. Tumor Biol. 2015, 36, 2737-2745 https://doi.org/10.1007/s13277-014-2898-5.

195. Qu, J.; Zhao, L.; Zhang, P.; Wang, J.; Xu, N.; Mi, W.; Jiang, X.; Zhang, C.; Qu, J. MicroRNA-195 Chemosensitizes Colon Cancer Cells to the Chemotherapeutic Drug Doxorubicin by Targeting the First Binding Site of BCL2L2 MRNA. J. Cell. Physiol. 2015, 230, 535-545 https://doi.org/10.1002/jcp.24366.

196. HE, H.; TIAN, W.; Chen, H.; DENG, Y. MicroRNA-101 Sensitizes Hepatocellular Carcinoma Cells to Doxorubicin-Induced Apoptosis via Targeting Mcl-1. Mol. Med. Rep. 2016, 13, 1923-1929 https://doi.org/10.3892/mmr.2015.4727.

197. Zeng, L.-P.; Hu, Z.-M.; Li, K.; Xia, K. MiR-222 Attenuates Cisplatin-Induced Cell Death by Targeting the PPP2R2A/Akt/MTOR Axis in Bladder Cancer Cells. J. Cell. Mol. Med. 2016, 20, 559-567 https://doi.org/10.1111/jcmm.12760.

198. Huang, N.; Wu, J.; Qiu, W.; Lyu, Q.; He, J.; Xie, W.; Xu, N.; Zhang, Y. MiR-15a and MiR-16 Induce Autophagy and Enhance Chemosensitivity of Camptothecin. Cancer Biol. Ther. 2015, 16, 941-948 https://doi.org/10.1080/15384047.2015.1040963.

199. Chatterjee, A.; Chattopadhyay, D.; Chakrabarti, G. MiR-16 Targets Bcl-2 in Paclitaxel-Resistant Lung Cancer Cells and Overexpression of MiR-16 along with MiR-17 Causes Unprecedented Sensitivity by Simultaneously Modulating Autophagy and Apoptosis. Cell. Signal. 2015, 27, 189-203 https://doi.org/10.1016/j.cellsig.2014.11.023.

200. Zhao, J.; Nie, Y.; Wang, H.; Lin, Y. MiR-181a Suppresses Autophagy and Sensitizes Gastric Cancer Cells to Cisplatin. Gene 2016, 576, 828-833 https://doi.org/10.1016/j.gene.2015.11.013.

201. Mu, W.; Hu, C.; Zhang, H.; Qu, Z.; Cen, J.; Qiu, Z.; Li, C.; Ren, H.; Li, Y.; He, X.; et al. MiR-27b Synergizes with Anticancer Drugs via P53 Activation and CYP1B1 Suppression. Cell Res. 2015, 25, 477-495 https://doi.org/10.1038/cr.2015.23.

202. Rieger, J.K.; Reutter, S.; Hofmann, U.; Schwab, M.; Zanger, U.M. Inflammation-Associated MicroRNA-130b Down-Regulates Cytochrome P450 Activities and Directly Targets CYP2C9. Drug Metab. Dispos. 2015, 43, 884-888 https://doi.org/10.1124/dmd.114.062844.

203. He, X.; Xiao, X.; Dong, L.; Wan, N.; Zhou, Z.; Deng, H.; Zhang, X. MiR-218 Regulates Cisplatin Chemosensitivity in Breast Cancer by Targeting BRCA1. Tumor Biol. 2015, 36, 2065-2075 https://doi.org/10.1007/s13277-014-2814-z.

204. Strumidło, A.; Skiba, S.; Scott, R.J.; Lubiński, J. The Potential Role of MiRNAs in Therapy of Breast and Ovarian Cancers 
Associated with BRCA1 Mutation. Hered. Cancer Clin. Pract. 2017, 15, 15 https://doi.org/10.1186/s13053-017-0076-7.

205. Chen, S.; Jiao, J.-W.; Sun, K.; Zong, Z.; Zhao, Y.; Chen, S.; Jiao, J.-W.; Sun, K.; Zong, Z. MicroRNA-133b Targets Glutathione S-Transferase $\pi$ Expression to Increase Ovarian Cancer Cell Sensitivity to Chemotherapy Drugs. Drug Des. Devel. Ther. 2015, 9, 5225-5235 https://doi.org/10.2147/DDDT.S87526. 